CARLOS RENOIR DO N. LIMA

\title{
ANÁLISE DA DEFORMAÇÃO POR FLUÊNCIA EM UMA VIGA DE CONCRETO ARMADO E PROTENDIDO: RETROANÁLISE E ALGORITMO GENÉTICO
}

Dissertação apresentada à Escola Politécnica da Universidade de São Paulo para obtenção do Título de Mestre em Engenharia 
CARLOS RENOIR DO N. LIMA

\section{ANÁLISE DA DEFORMAÇÃO POR FLUÊNCIA EM UMA VIGA DE CONCRETO ARMADO E PROTENDIDO: RETROANÁLISE E} ALGORITMO GENÉTICO

Dissertação apresentada à Escola Politécnica da Universidade de São Paulo para obtenção do Título de Mestre em Engenharia

Área de concentração:

Engenharia de Estruturas

Orientador:

Prof. Dr. João Cyro André

São Paulo 
Este exemplar foi revisado e alterado em relação à versão original, sob responsabilidade única do autor e com a anuência de seu orientador.

São Paulo, de maio de 2007

Assinatura do autor

Assinatura do orientador

FICHA CATALOGRÁFICA

\section{Lima, Carlos Renoir do Nascimento}

Análise da deformação por fluência em uma viga de concreto armado e protendido : retroanálise e algoritmo genético / C.R.N. Lima. - ed.rev. - São Paulo, 2007.

76 p.

Dissertação (Mestrado) - Escola Politécnica da Universidade de São Paulo. Departamento de Engenharia de Estruturas e Fundações.

1. Algoritmos genéticos 2. Mínimos quadrados 3. Concreto armado I. Universidade de São Paulo. Escola Politécnica. Departamento de Engenharia de Estruturas e Fundações II. t. 
Aos meus pais, Raimundo e Raimunda (in memoriam), e aos meus irmãos Rembrandt e Rodrigo (in memoriam). 


\section{AGRADECIMENTOS}

Ao longo desta caminhada, muitas pessoas direta ou indiretamente me auxiliaram para que pudesse desenvolver este trabalho. O meu mais sincero muito obrigado a todos!.

Ao professor orientador, Dr. João Cyro André, pelo carinho e cordialidade que tratou desse estudo. Ao professor Dr. Edgard pelas suas contribuições no direcionamento desse trabalho.

Ao meu pai Raimundo que através do seu exemplo, ensinou-me a lutar com determinação, superando todos os limites.

À Terezinha, Luiz Paulo e Aline, por terem confiado e dado todo o apoio necessário do início ao fim de mais esta etapa em minha vida. Obrigado pelo carinho e amizade.

Aos amigos Carlos Rezende, Igor Pereira e Luiz Cláudio, bem como a Ricardo, Betinha, Marquinhos, Calebe e Silvia, que me ensinaram muito sobre a vida. Foi muito gratificante ter convivido com vocês nesse período de aprendizado.

Aos meus novos amigos, Debinha, Jeff e Mago pela companhia e força que me passaram.

Ao meu irmão, Rembrandt, parentes e amigos de longa data.

À CAPES, pela bolsa de mestrado, aos funcionários e professores da USP, em especial modo ao José Cristiano, bem como aos colegas do LMC (Laboratório de Mecânica Computacional). 


\section{RESUMO}

Este trabalho apresenta um estudo sobre a deformação por fluência em uma viga de concreto armado e protendido ensaiada no LABEST - Laboratório da Tecnologia do Betão e do Comportamento Estrutural do Departamento de Engenharia Civil da Faculdade de Engenharia da Universidade do Porto, Portugal. A partir das deformações lineares específicas medidas no experimento, determinam-se: a sua parcela instantânea e a devido à fluência do concreto, e se faz uma comparação entre a curva de função de fluência obtida pela medição das deformações lineares específicas e as curvas geradas pelo CEB, CEB-Santos (função modificada do CEB por Santos) e pelo modelo de três parâmetros de Boltzmann. A obtenção das curvas de função de fluência do CEB-Santos e do modelo de Boltzmann exige a identificação de parâmetros para cada modelo, que se faz por técnica de retroanálise e por Algoritmos Genéticos.

Palavras-chave: Concreto, Fluência, Retroanálise, Algoritmos Genéticos. 


\section{ABSTRACT}

This paper presents an analysis about creep strain of a reinforced and prestressed concrete beam assayed in the LABEST - Laboratory for the Concrete Technology and Structural Behaviour - Department of Civil Engineering, College of Engineering, University of Porto, Portugal. The instantaneous parcels and the creep of concrete are determined by strain measured in the experiment. Afterward, the curves of creep functions, obtained from the measurement of the strain, have been compared with the generated curves by CEB, CEB-Santos (modified function of CEB by Santos) and Boltzmann model. Both CEB-Santos and Boltzmann curves requires the identification of the parameters for each model. These parameters can be established through techniques as back analysis and Genetic Algorithms.

Keywords: Concrete, Creep, Back analisys, Genetic Algorithm. 


\section{LISTA DE FIGURAS}

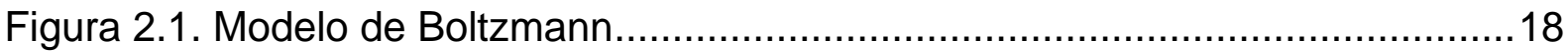

Figura 2.2. Diagrama da função de fluência.......................................................20

Figura 2.3. Diagramas de tensão e deformação no tempo .....................................20

Figura 5.1. Viga de concreto armado e protendido (medidas em $\mathrm{cm}$ ) .....................42

Figura 5.2. Viga em concreto armado e protendido ............................................4 44

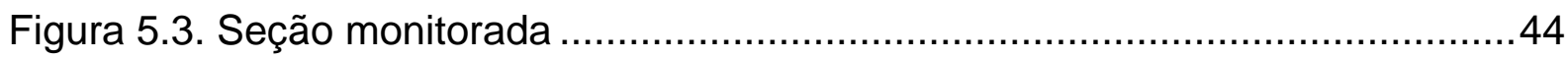

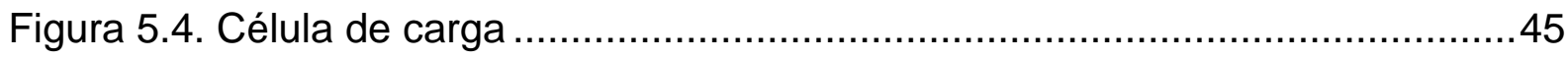

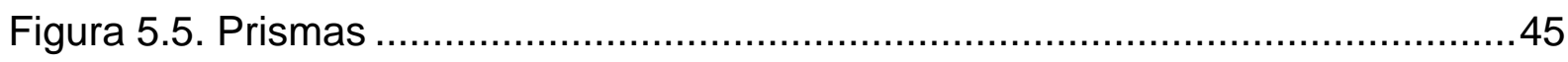

Figura 5.6. Deformações lineares específicas medidas nas fibras superiores ..........46

Figura 5.7. Deformações lineares específicas medidas nas fibras inferiores............47

Figura 6.1. Ferramenta do MATLAB para resolução de problemas via AG's............50

Figura 6.2. Interface gráfica: Parâmetros de entrada .............................................50

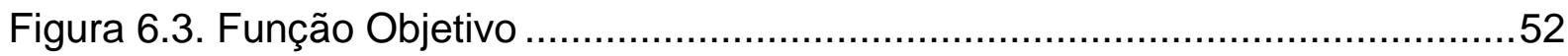

Figura 6.4. Curvas de funções de fluência para o instante de aplicação da protensão

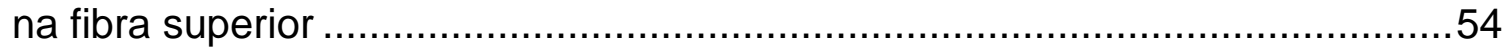

Figura 6.5. Convergência da função objetivo na retroanálise (a) e da solução em AG (b) para o instante de aplicação da protensão na fibra superior .........................54

Figura 6.6. Curvas de funções de fluência para o instante de aplicação da protensão

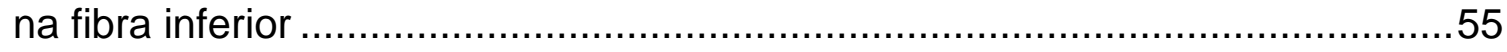

Figura 6.7. Convergência da função objetivo na retroanálise (a) e da solução em AG (b) para o instante de aplicação da protensão na fibra inferior ....

Figura 6.8. Curvas de funções de fluência para a $1^{a}$ aplicação da ação de longa duração na fibra superior .....

Figura 6.9. Convergência da função objetivo na retroanálise (a) e da solução em AG (b) para a $1^{a}$ aplicação da ação de longa duração na fibra superior.

Figura 6.10. Curvas de funções de fluência para a $1^{\mathrm{a}}$ aplicação da ação de longa duração na fibra inferior 
Figura 6.11. Convergência da função objetivo na retroanálise (a) e da solução em AG (b) para a $1^{\mathrm{a}}$ aplicação da ação de longa duração na fibra inferior .....

Figura 6.12. Curvas de funções de fluência para a descarga da ação de longa duração na fibra superior

Figura 6.13. Convergência da função objetivo na retroanálise (a) e da solução em AG (b) para a descarga da ação de longa duração na fibra superior 60

Figura 6.14. Curvas de funções de fluência para a descarga da ação de longa duração na fibra inferior

Figura 6.15. Convergência da função objetivo na retroanálise (a) e da solução em AG (b) para a descarga da ação de longa duração na fibra inferior.

Figura 6.16. Curvas de funções de fluência para a $2^{\mathrm{a}}$ aplicação da ação de longa duração na fibra superior 63

Figura 6.17. Convergência da função objetivo na retroanálise (a) e da solução em AG (b) para a $2^{\mathrm{a}}$ aplicação da ação de longa duração na fibra superior.....

Figura 6.18. Curvas de funções de fluência para a $2^{\mathrm{a}}$ aplicação da ação de longa duração na fibra inferior 64

Figura 6.19. Convergência da função objetivo na retroanálise (a) e da solução em AG (b) para a $2^{\mathrm{a}}$ aplicação da ação de longa duração na fibra inferior.. 65 


\section{니STA DE TABELAS}

Tabela 4.1. Representação binária de cromossomos .......................................36

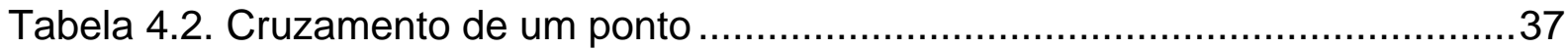

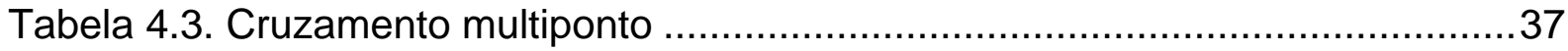

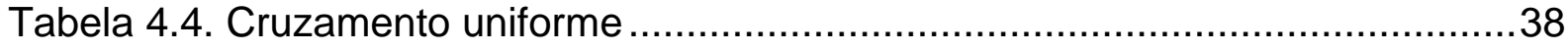

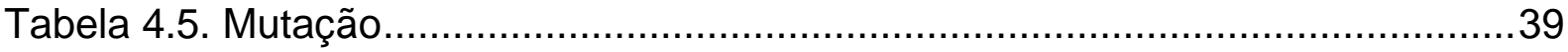

Tabela 5.1. Ações na viga ................................................................. 43

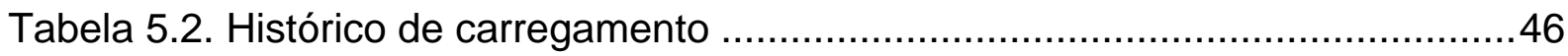

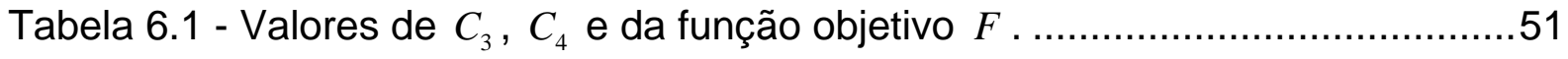

Tabela 6.2 - Valores de $E_{0}, E_{1}$ e $\eta_{1}$ para o modelo de Boltzmann. ........................52 


\section{SUMÁRIO}

1. Introdução _ 12

1.1. Considerações gerais

1.2. Objetivos 12

1.3. Estrutura da dissertação ___ 13

2. Funções de fluência ___ 15

2.1. Fluência _ 15

2.2. Fluência no concreto

2.3. Retração no concreto

2.4. Decomposição das parcelas de deformações lineares no concreto ___ 16

2.5. Modelo de Boltzmann

2.6. Modelo CEB__ 20

2.7. Modelo CEB-Santos _ 24

3. Retroanálise 25

3.1. Definição — 25

3.2. Critério de identificação___ 26

3.3. Critério dos mínimos quadrados 26

3.4. Algorítmo de minimização___ 27

3.5. Método de Newton-Raphson__ 29

3.6. Método de Gauss-Newton __ 31

3.7. Método de Levenberg-Marquardt __ 31

4. Algorítmos genéticos 33

4.1. Introdução __ 33

4.2. Definições _ 34

4.3. Parâmetros de influência nos Algoritmos Genéticos __ 39

4.4. Estrutura dos Algoritmos Genéticos _ 40 
5. Modelo Experimental 42

5.1. Modelo analisado experimentalmente 42

5.2. Monitoramento do experimento 43

5.3. Resultados experimentais__ 46

6. Resultados_ 48

6.1. Introdução _ 48

6.2. Parâmetros identificados___ 49

6.3. Resultados em gráficos

7. Observações finais _ 66

Referências _ 68

Apêndice $A \longrightarrow 71$ 


\section{INTRODUÇÃO}

\subsection{CONSIDERAÇÕES GERAIS}

O comportamento do concreto é caracterizado por uma complexa relação entre as tensões e as deformações no tempo. Ao se aplicar um carregamento em uma estrutura de concreto, inicialmente, a estrutura terá uma deformação instantânea, a qual é seguida de um acréscimo de deformação ao longo do tempo. Fenômeno esse chamado de fluência.

Em razão da complexidade e grandiosidade das estruturas modernas, o conhecimento e a consideração da fluência no concreto são de grande importância para a correta análise das deformações de elementos estruturais e na perda de tensão em peças protendidas, sendo necessária à consideração de seus efeitos no dimensionamento de estruturas de concreto.

A compreensão do fenômeno da fluência, sua quantificação em elementos estruturais e situações relevantes são indispensáveis. Para prever esse comportamento do concreto e avaliar os efeitos que os carregamentos podem ocasionar ao longo do tempo, muitos modelos foram propostos por diferentes autores e normas.

\subsection{OBJETIVOS}

Sousa et al. (2002) e Horvath (2005) fizeram um estudo baseado no ajuste de curvas de deformações, em uma viga de concreto armado e protendido, simplesmente apoiada. Este ajuste era baseado na inserção de coeficientes no modelo CEB-FIP 
(Model Code 1990) proposto por Santos (2001 apud SOUSA; FÉLIX; FIGUEIRAS, 2002).

O objetivo deste trabalho está em fazer uma análise das funções de fluência referente aos diversos intervalos de carregamento em que foi submetida à viga ensaiada. Bem como, a análise das funções geradas pelos modelos do CEB, CEBSantos e Boltzmann. Ou seja, fazer uma interpretação das curvas geradas pelas diversas funções de fluência obtidas por meio de dados medidos e da identificação de parâmetros que melhor ajustam o modelo em estudo, pela técnica de retroanálise.

Foi utilizado no desenvolvimento desta dissertação o software MATLAB por ser uma poderosa ferramenta computacional e de fácil linguagem de programação. Criou-se, a partir deste, um programa com a formulação do modelo CEB-Santos e Boltzmann. Além disso, implementou-se um programa para a identificação dos parâmetros das curvas de função de fluência dos modelos CEB-Santos e Boltzmann, por técnica de retroanálise que utiliza o método de Levenberg-Marquardt para a minimização da função objetivo. Do mesmo modo, utilizaram-se os Algoritmos Genéticos para a identificação dos parâmetros, por meio de uma ferramenta disponível no toolbox do MATLAB.

\subsection{ESTRUTURA DA DISSERTAÇÃO}

A dissertação está estruturada em sete capítulos, incluindo este capítulo introdutório.

As deformações lineares específicas que ocorrem no concreto são definidas no capítulo 2. Também, definem-se os modelos estudados para a representação do comportamento das deformações no concreto, como o modelo do CEB, CEB-Santos e Boltzmann. 
O capítulo 3 destina-se a explicitar de forma sucinta as técnicas de retroanálise. Definem-se aqui os critérios de identificação, o algoritmo de minimização e os métodos de minimização, como Newton-Raphson, Gauss-Newton e LevenbergMarquardt.

No quarto capítulo faz-se uma abordagem breve sobre os Algoritmos Genéticos, com introdução, definições, parâmetros de influência e por fim a sua estrutura.

O capitulo 5 destina-se a um detalhamento do modelo experimental analisado, como propriedades físicas e monitoramento da estrutura, bem como apresentar os resultados obtidos pelo modelo experimental, por monitoramento contínuo das deformações lineares específicas.

No capítulo 6 são apresentados os resultados obtidos, por meio dos modelos propostos, em forma de gráficos e tabelas, gráficos estes que exibem as curvas geradas pelas diversas funções de fluência.

Apresentam-se no capitulo 7 as observações finais, com suas principais conclusões, contribuições e recomendações quanto a desenvolvimento de futuros trabalhos. 


\title{
2. FUNÇÕES DE FLUÊNCIA
}

\author{
2.1. FLUÊNCIA
}

A fluência é definida como um fenômeno pelo qual um corpo sofre um aumento gradual de deformação ao longo do tempo quando submetido a um estado de tensão constante no tempo. Esse fenômeno pode ser observado no deslizamento de geleiras, rochas e grandes massas de solo. A fluência pode ocorrer em muitos materiais usados na engenharia de construção como betume, cerâmicas, metais e concreto.

O fenômeno fluência pode ser caracterizado por meio de modelos reológicos, ou seja, por modelos matemáticos que simulam o comportamento dos materiais a partir de fenômenos como elasticidade, plasticidade e viscosidade.

Com a combinação de modelos básicos unidimensionais (elástico, plástico e viscoso) obtêm-se os modelos conjugados (ou seja, com a combinação em série ou em paralelo, desses modelos básicos ou mesmo de outros modelos conjugados) para descrever os comportamentos mais complexos, como a fluência do concreto.

\subsection{FLUENNCIA NO CONCRETO}

A fluência no concreto depende essencialmente do teor de umidade do concreto, da umidade ambiente, das dimensões do elemento estrutural, da composição do concreto, da temperatura ambiente e do tipo de cimento utilizado. 
O concreto pode ser entendido como um material viscoelástico, onde o módulo de elasticidade inicial e as funções de fluência dependem da idade do concreto por ocasião da aplicação do carregamento.

\subsection{RETRAÇÃO NO CONCRETO}

"Do mesmo modo que a fluência, uma pasta de cimento saturada não permanecerá dimensionalmente estável quando exposta a umidades ambientais que estão abaixo da saturação, principalmente porque a perda de água fisicamente adsorvida do C-SH resulta em uma deformação de retração." (MEHTA; MONTEIRO, 1994).

A retração do concreto é um fenômeno que independe de ações de cargas externas. Contudo, dependente da variação de umidade no concreto, na tendência a permanecerem em equilíbrio a umidade do concreto e a umidade do meio exterior. No processo da retração, a água é inicialmente expulsa das fibras externas o que gera deformações diferenciais entre a periferia e o miolo, gerando tensões internas capazes de provocar fissuração do concreto.

\subsection{DECOMPOSIÇÃO DAS PARCELAS DE DEFORMAÇÕES LINEARES NO CONCRETO}

Como a deformação por fluência do concreto pode ser várias vezes maiores que a deformação logo após o instante do carregamento, este fenômeno tem considerável importância nas estruturas.

Segundo Neville (1997), "A fluência pode levar a deflexões excessivas de elementos estruturais e causar outros problemas de utilização, principalmente em edifícios de grande altura e pontes muito longas". 
A deformação linear específica (ou alongamento) total em um instante $t, \varepsilon_{c}(t)$, de uma fibra de concreto solicitada no instante $t_{0}$ com tensão constante $\sigma_{c}\left(t_{0}\right)$ pode ser expressa por:

$$
\varepsilon_{c}(t)=\varepsilon_{c i}\left(t_{0}\right)+\varepsilon_{c c}(t)+\varepsilon_{c s}(t)+\varepsilon_{c T}(t),
$$

em que $\varepsilon_{c i}\left(t_{0}\right), \quad \varepsilon_{c c}(t), \quad \varepsilon_{c s}(t)$ e $\varepsilon_{c T}(t)$, são, respectivamente, as parcelas de deformações lineares específicas, instantânea no instante $t_{0}$, por fluência em um instante $t>t_{0}$, por retração e por variação de temperatura.

Para medidas de deformações efetuadas por extensômetros perfeitamente autocompensados para os efeitos da temperatura, a Equação (2.1) se reduz a:

$$
\varepsilon_{c}(t)=\varepsilon_{c i}\left(t_{0}\right)+\varepsilon_{c c}(t)+\varepsilon_{c s}(t) .
$$

As parcelas de fluência e de retração da deformação linear específica total caracterizam o fenômeno do aparecimento de deformações não imediatas no concreto, ou seja, a sua viscosidade, conforme SOUZA LIMA et al. (1976). Na retração, ocorrem deformações diferidas sem a aplicação de carregamento externo. Na fluência, as deformações diferidas resultam de carregamento externo constante.

\subsection{MODELO DE BOLTZMANN}

O modelo de Boltzmann é um modelo conjugado simples que pode ser utilizado na representação do comportamento do concreto. É um modelo reológico de três parâmetros que combina uma parcela elástica, que representa a deformação imediata, e uma parcela viscoelástica, que define a fluência no concreto. 


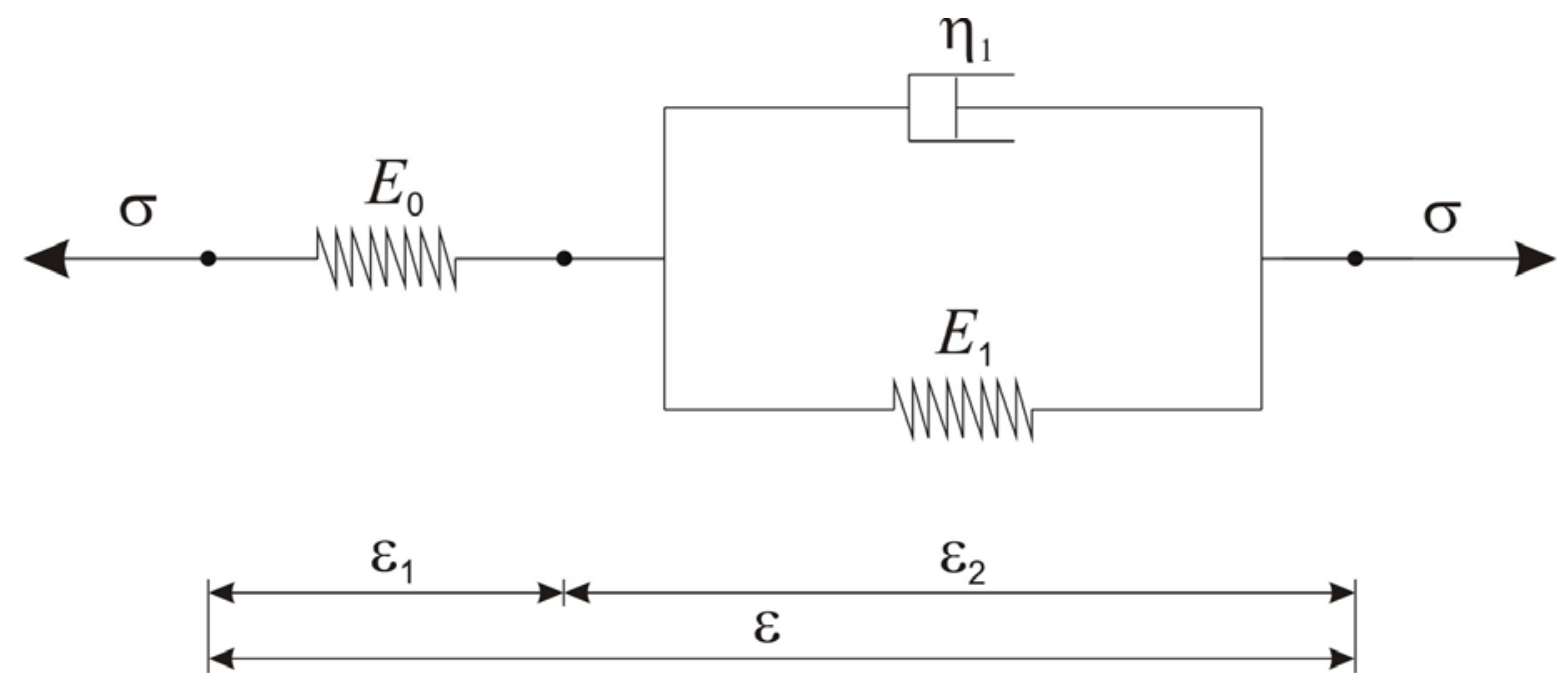

Figura 2.1. Modelo de Boltzmann

De acordo com Figura 2.1 ao aplicar uma tensão inicial $\sigma$, aparece uma deformação imediata exclusivamente pela parcela $E_{0}$. Com o tempo, o elemento viscoso passa a funcionar e assim a deformação lenta se manifesta no modelo. A deformação total do modelo é então definida pela soma das parcelas da deformação imediata e a deformação lenta

$$
\varepsilon=\varepsilon_{1}+\varepsilon_{2}
$$

sendo a parcela elástica dada por

$$
\varepsilon_{1}=\frac{\sigma}{E_{0}} ; \dot{\varepsilon}_{1}=\frac{\dot{\sigma}}{E_{0}}
$$

e a parcela viscoelástica por

$$
\varepsilon_{2}=\varepsilon-\frac{\sigma}{E_{0}}
$$

Em um instante $t$ a tensão total será

$$
\sigma=E_{0} \varepsilon_{1}=E_{1} \varepsilon_{2}+\eta_{1} \dot{\varepsilon}_{2}
$$

e utilizando-se das Equações (2.4) e (2.5) em (2.6) decorre a equação constitutiva do modelo

$$
\eta_{1} \dot{\sigma}+\left(E_{0}+E_{1}\right) \sigma=E_{0} \eta_{1} \dot{\varepsilon}+E_{0} E_{1} \varepsilon
$$


Fazendo-se $\sigma(t)=\sigma_{0}$, ou seja, aplicando uma tensão constante em(2.7), obtém-se:

$$
E_{0} \eta_{1} \dot{\varepsilon}+E_{0} E_{1} \varepsilon=\left(E_{0}+E_{1}\right) \sigma_{0},
$$

cuja a integração, com a condição inicial $\varepsilon(0)=\frac{\sigma_{0}}{E_{0}}$ leva a

$$
\varepsilon(t)=\sigma_{0}\left(\frac{E_{0}+E_{1}}{E_{1} E_{0}}-\frac{1}{E_{1}} e^{-\theta t}\right)
$$

onde

$$
\theta=\frac{E_{1}}{\eta_{1}}
$$

Levando o módulo de deformação a um tempo infinito, obtém-se:

$$
E_{\infty}=\frac{E_{1} E_{0}}{E_{0}+E_{1}} .
$$

O decaimento do módulo de elasticidade com o tempo, de $E_{0}$ para $E_{\infty}$, é representado por

$$
\frac{1}{E(t)}=\frac{\varepsilon(t)}{\sigma_{0}}=\frac{1}{E_{\infty}}-\frac{1}{E_{1}} e^{-\theta t},
$$

esta diminuição aparente do módulo de elasticidade sob tensão constante, leva a um aumento das deformações com o tempo e este fenômeno é chamado de fluência.

A expressão (2.12) pode ser reescrita na forma

$$
J\left(t, t_{0}\right)=\frac{1}{E\left(t, t_{0}\right)}=\frac{1}{E_{\infty}}-\frac{1}{E_{1}} e^{-\theta\left(t-t_{0}\right)},
$$

onde (2.13) é chamada de função de fluência e é representada graficamente pela Figura 2.2.

Deste modo, a Equação (2.9) pode ser posta na forma

$$
\varepsilon\left(t, t_{0}\right)=\sigma_{0} J\left(t, t_{0}\right) .
$$

Na Figura 2.3 apresentam-se os diagramas de tensão e deformação no tempo, a partir de um carregamento aplicado no tempo $t_{0}$. 


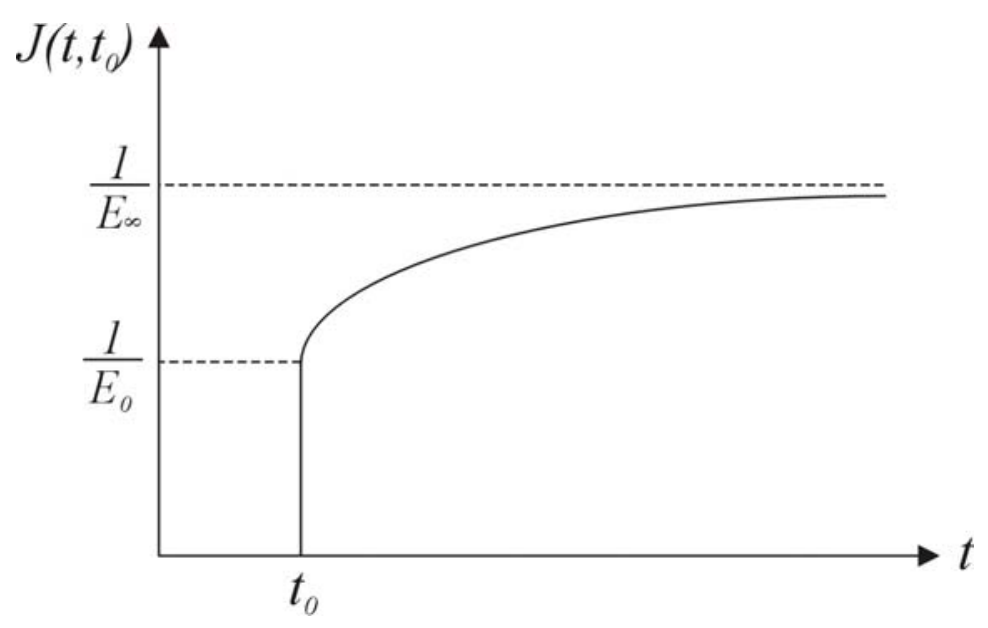

Figura 2.2. Diagrama da função de fluência
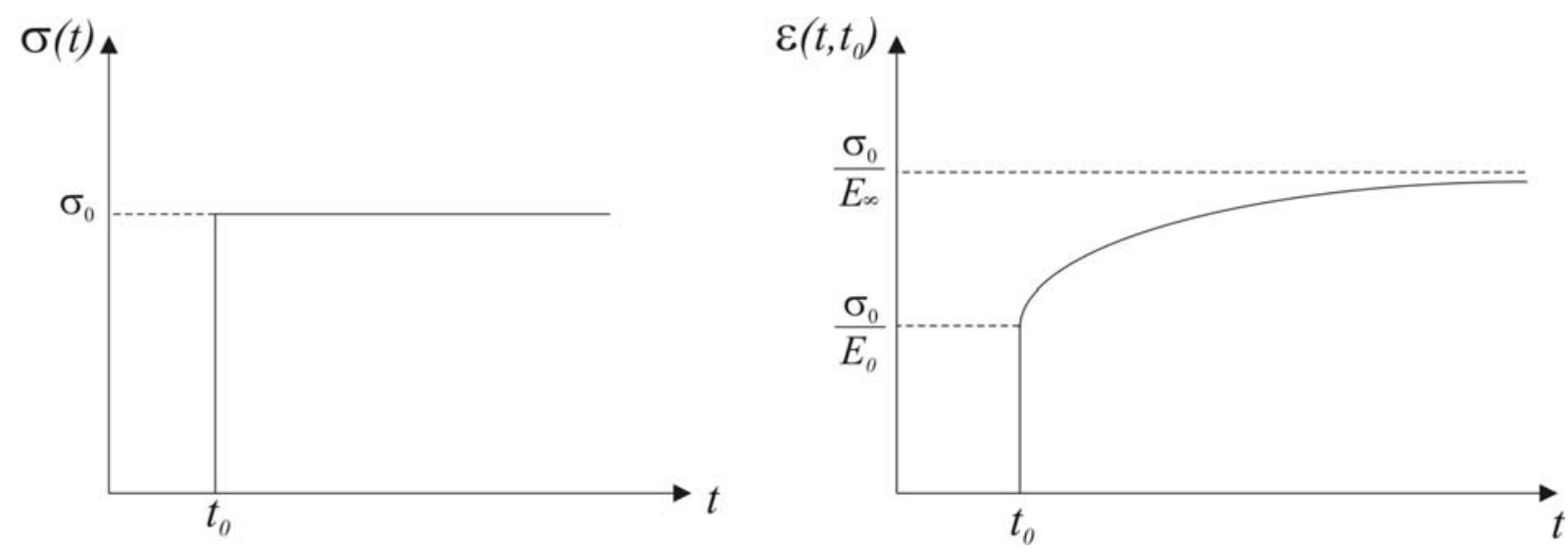

Figura 2.3. Diagramas de tensão e deformação no tempo

Como se pretende utilizar o modelo de Boltzmann no concreto admitiu-se que os valores dos parâmetros $E_{0}, E_{1}$ e $\eta_{1}$ são funções de $t_{0}$.

\subsection{MODELO CEB}

O Comite Euro-International du Beton (CEB) considera um modelo para a fluência para concreto estrutural com $f_{c k}$ de $12 \mathrm{MPa}$ a $80 \mathrm{MPa}$ sujeito unicamente a tensões de compressão de $\left|\sigma_{c}\right|<0,4 f_{c m}\left(t_{0}\right)$, dependente de temperaturas médias entre $5^{\circ} \mathrm{C}$ e 
$30^{\circ} \mathrm{C}$, e umidades relativas médias de $40 \%$ a $100 \%$. Onde $f_{c k}$ e $f_{c m}\left(t_{0}\right)$ representam, respectivamente, as resistências característica e média do concreto no instante do carregamento $t_{0}$.

O modelo CEB-FIP (Model Code 1990) não estima as propriedades reológicas locais dentro da seção transversal do concreto, tal como variações devidas às tensões internas, umidade ou efeitos locais de fissuras. O modelo não é aplicável para:

- Concreto sujeito a temperaturas extremas, nem altas (como reatores nucleares) e nem baixas;

- Locais onde a média da umidade relativa fica abaixo de $40 \%$ e

- Estruturas de concreto com agregados leves.

Embora muitos estudos recentes levem em conta uma análise não-linear da fluência em estruturas de concreto, praticamente quase todas as aplicações ainda contam com a hipótese da linearidade. Isto se confirma pelas atuais propostas das normas.

Para tensões que são constantes ao longo do tempo, a linearidade significa que as deformações $\varepsilon(t)$ no instante $t$ são proporcionais às tensões $\sigma$ e que a resposta da fluência é totalmente caracterizada em conformidade com a função $J\left(t, t_{0}\right)$.

A deformação linear específica por fluência num instante $t$ considerando uma tensão constante $\left(\sigma_{c}\right)$ aplicada no instante $t_{0}$ é definida pelo CEB como

$$
\varepsilon_{c c}\left(t, t_{0}\right)=\frac{\sigma_{c}\left(t_{0}\right)}{E_{c i}} \phi\left(t, t_{0}\right),
$$

em que $E_{c i}$ é o módulo de elasticidade aos 28 dias de idade,

$$
E_{c i}=E_{c 0}\left[\frac{f_{c k}+\Delta f}{f_{c m 0}}\right]^{1 / 3}
$$

em que $\Delta f=8 \mathrm{MPa}, f_{c m 0}=10 \mathrm{MPa}, E_{c 0}=2,15 \times 10^{4} \mathrm{MPa}$ e $\phi\left(t, t_{0}\right)$ é o coeficiente de fluência que define as propriedades da fluência, e é expresso por: 


$$
\phi\left(t, t_{0}\right)=\phi_{0} \beta_{c}\left(t-t_{0}\right),
$$

onde $\phi_{0}$ é o coeficiente de fluência nominal e $\beta_{c}$ é o coeficiente correspondente ao desenvolvimento da fluência com o tempo depois do carregamento.

A expressão do coeficiente de fluência nominal é dada por:

$$
\phi_{0}=\phi_{R H} \beta\left(f_{c m}\right) \beta\left(t_{0}\right) \text {, }
$$

com

$$
\begin{gathered}
\phi_{R H}=1+\frac{1-R H / R H_{0}}{0,46\left(h / h_{0}\right)^{1 / 3}}, \\
\beta\left(f_{c m}\right)=\frac{5,3}{\left(f_{c m} / f_{c m 0}\right)^{0,5}}, \\
\beta\left(t_{0}\right)=\frac{1}{0,1+\left(t_{0} / t_{1}\right)^{0,2}},
\end{gathered}
$$

onde $h=2 A_{c} / u$ é a espessura equivalente do elemento expressa em milímetros $(\mathrm{mm}), h_{0}=100 \mathrm{~mm}, A_{c}$ é a área da seção transversal $\left(\mathrm{mm}^{2}\right), u$ é o perímetro do elemento em contato com a atmosfera $(\mathrm{mm}), R H$ é a porcentagem da umidade relativa do meio ambiente, $R H_{0}=100 \%$ e $t_{1}=1$ dia .

O coeficiente $\beta_{c}$ que determina o desenvolvimento da fluência com o tempo é explicitado por:

$$
\beta_{c}\left(t-t_{0}\right)=\left[\frac{\left(t-t_{0}\right) / t_{1}}{\beta_{H}+\left(t-t_{0}\right) / t_{1}}\right]^{0,3}
$$

em que

$$
\beta_{H}=150\left\{1+\left(1,2 \frac{R H}{R H_{0}}\right)^{18}\right\} \frac{h}{h_{0}}+250 \leq 1500 .
$$

O CEB define um instante $t_{0}$ (idade do carregamento) que varia de acordo com o tipo de cimento e da variação de temperatura na maturidade do concreto, conforme a Equação (2.24) 


$$
t_{0}=t_{0, T}\left(\frac{9}{2+\left(t_{0, T} / t_{1, T}\right)^{1,2}}+1\right)^{\alpha} \geq 0,5 \text { dias }
$$

em que

$$
t_{0, T}=\sum_{i=1}^{n} \Delta t_{i} \exp \left[13,65-\frac{4000}{273+T\left(\Delta t_{i}\right) / T_{0}}\right]
$$

e $\alpha$ é o expoente que depende do tipo de cimento e pode assumir valores $-1,0$ e 1 , respectivamente, para cimento de endurecimento lento (SL), normal ou rápido (N e $\mathrm{R}$ ) e rápido e de alta resistência (RS).

Também são definidos os parâmetros de entrada $t_{0, T}$ como a idade do concreto no carregamento, em dias, ajustada em função da temperatura, $\Delta t_{i}$ é o número de dias em que uma temperatura $T$ prevalece, $T\left(\Delta t_{i}\right)$ é a temperatura em ${ }^{\circ} \mathrm{C}$ durante o intervalo de tempo $\Delta t_{i}, t_{1, T}=1$ dia e $T_{0}=1^{\circ} \mathrm{C}$.

O CEB também define uma equação para a deformação por fluência no concreto devido a tensões ou deformações variáveis, e admitindo-se a hipótese da linearidade, que implica no princípio da superposição, essa equação é expressa por

$$
\varepsilon_{c c}\left(t, t_{0}\right)=\frac{\sigma_{c}\left(t_{0}\right)}{E_{c i}} \phi\left(t, t_{0}\right)+\int_{t_{0}}^{t} \frac{\phi(t, \tau)}{E_{c i}} \frac{\partial \sigma_{c}(\tau)}{\partial \tau} d \tau,
$$

onde $\int_{t_{0}}^{t} \frac{\phi(t, \tau)}{E_{c i}} \frac{\partial \sigma_{c}(\tau)}{\partial \tau} d \tau$ é uma integral hereditária.

A função de fluência proposta pelo CEB é definida como

$$
J\left(t, t_{0}\right)=\frac{\varepsilon_{c \sigma}\left(t, t_{0}\right)}{\sigma_{c}\left(t_{0}\right)}
$$

onde $\varepsilon_{c \sigma}\left(t, t_{0}\right)$ é a soma das parcelas de deformação linear específica instantânea e deformação linear específica por fluência, ou seja,

$$
\varepsilon_{c \sigma}\left(t, t_{0}\right)=\varepsilon_{c i}\left(t_{0}\right)+\varepsilon_{c c}\left(t, t_{0}\right),
$$


em que

$$
\varepsilon_{c i}\left(t, t_{0}\right)=\frac{\sigma_{c}\left(t_{0}\right)}{E\left(t_{0}\right)}
$$

e $E\left(t_{0}\right)$ é o módulo de elasticidade no instante $t_{0}$ de aplicação do carregamento.

Então a expressão (2.27) que representa a função de fluência do CEB pode ser reescrita na forma

$$
J\left(t, t_{0}\right)=\left(\frac{1}{E\left(t_{0}\right)}+\frac{1}{E_{c i}} \phi\left(t, t_{0}\right)\right) .
$$

\subsection{MODELO CEB-SANTOS}

Santos (2001 apud SOUSA; FÉLIX; FIGUEIRAS, 2002) propôs um ajuste da curva do coeficiente de fluência proposta pelo modelo do CEB. Tal ajuste consiste em inserir coeficientes $C_{3}$ e $C_{4}$ respectivamente nas equações (2.18) e (2.22) conforme se mostra nas expressões:

$$
\begin{gathered}
\phi_{0}=\phi_{R H} \beta\left(f_{c m}\right) \beta\left(t_{0}\right) C_{3} \mathrm{e} \\
\beta_{c}\left(t-t_{0}\right)=\left[\frac{\left(t-t_{0}\right) / t_{1}}{\beta_{H}+\left(t-t_{0}\right) / t_{1}}\right]^{0,3 C_{4}} .
\end{gathered}
$$

O coeficiente $C_{3}$ afeta o valor da fluência ao tempo infinito e $C_{4}$ corrige o seu desenvolvimento no tempo.

A Equação (2.33) representa a função de fluência para o modelo CEB-Santos

$$
J\left(t, t_{0}, C_{3}, C_{4}\right)=\left(\frac{1}{E\left(t_{0}\right)}+\frac{1}{E_{c i}} \phi\left(t, t_{0}, C_{3}, C_{4}\right)\right) .
$$




\section{RETROANÁLISE}

\subsection{DEFINIÇÃO}

As técnicas de retroanálise permitem a identificação de parâmetros que melhor representem o modelo físico, ou seja, que melhor ajustem os valores calculados aos valores obtidos em campo. Geralmente, esses parâmetros estão relacionados à geometria da estrutura, às propriedades dos materiais constituintes ou, até mesmo, associados ao carregamento. A técnica de retroanálise adotada neste trabalho, que a seguir se apresenta de forma sucinta, está detalhada em Costa $(2000,2006)$.

O processo que descreve a retroanálise é ilustrado na Figura 3.1.

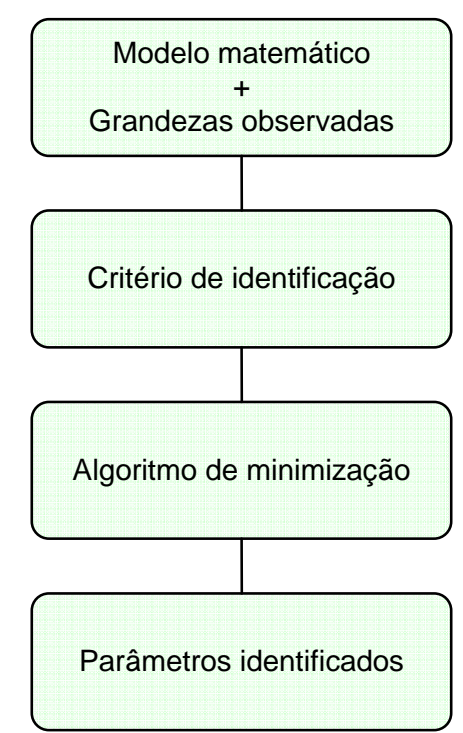

Figura 3.1. Processo de retroanálise 


\subsection{CRITÉRIO DE IDENTIFICAÇÃO}

Com o modelo matemático para análise estrutural bem definido, ou seja, geometria bem definida e ações bem caracterizadas, a técnica da retroanálise se reduz à identificação de parâmetros que propiciam a melhor aderência entre valores medidos e valores calculados de acordo com determinado critério de identificação.

Os critérios dos mínimos quadrados, de Markov, da máxima verossimilhança, da máxima verossimilhança com informação prévia e do mínimo risco são os critérios mais utilizados. São critérios estabelecidos pela diferença entre os valores calculados e os medidos e se diferenciam pelo grau de informação prévia disponível do problema. Este é o primeiro passo para a formulação de um problema da retroanálise.

O critério dos mínimos quadrados é o mais simples dentre os citados anteriormente e é o critério adotado neste trabalho. Um maior detalhamento dos demais critérios de identificação citados anteriormente é encontrado em Costa (2006).

\subsection{CRITÉRIO DOS MÍNIMOS QUADRADOS}

No caso das medidas efetuadas serem independentes entre si e de não serem utilizadas informações prévias, o critério de identificação se reduz ao dos mínimos quadrados.

O critério dos mínimos quadrados é simples e não pressupõe qualquer tipo de conhecimento prévio. Ele consiste em minimizar o quadrado da diferença entre os valores medidos, $y^{*}$, e os valores estimados pelo modelo, $y(p)$. Assim, a função objetivo pode ser expressa como:

$$
F(p)=\left[y^{*}-y(p)\right]^{T}\left[y^{*}-y(p)\right] .
$$


A solução para o problema é obtida pela identificação dos parâmetros que torna mínima a diferença entre esses valores, ou seja, que minimizam a função objetivo.

\subsection{ALGORÍTMO DE MINIMIZAÇÃO}

A minimização de uma função, que no caso é a função objetivo, consiste em encontrar os $n$ parâmetros que minimizam a função objetivo de acordo com 0 critério de identificação adotado.

Na Figura 3.2 ilustra-se o processo iterativo utilizado para elaboração de algoritmo de minimização partindo de um vetor de parâmetros iniciais estimados $\left(p_{0}\right)$.

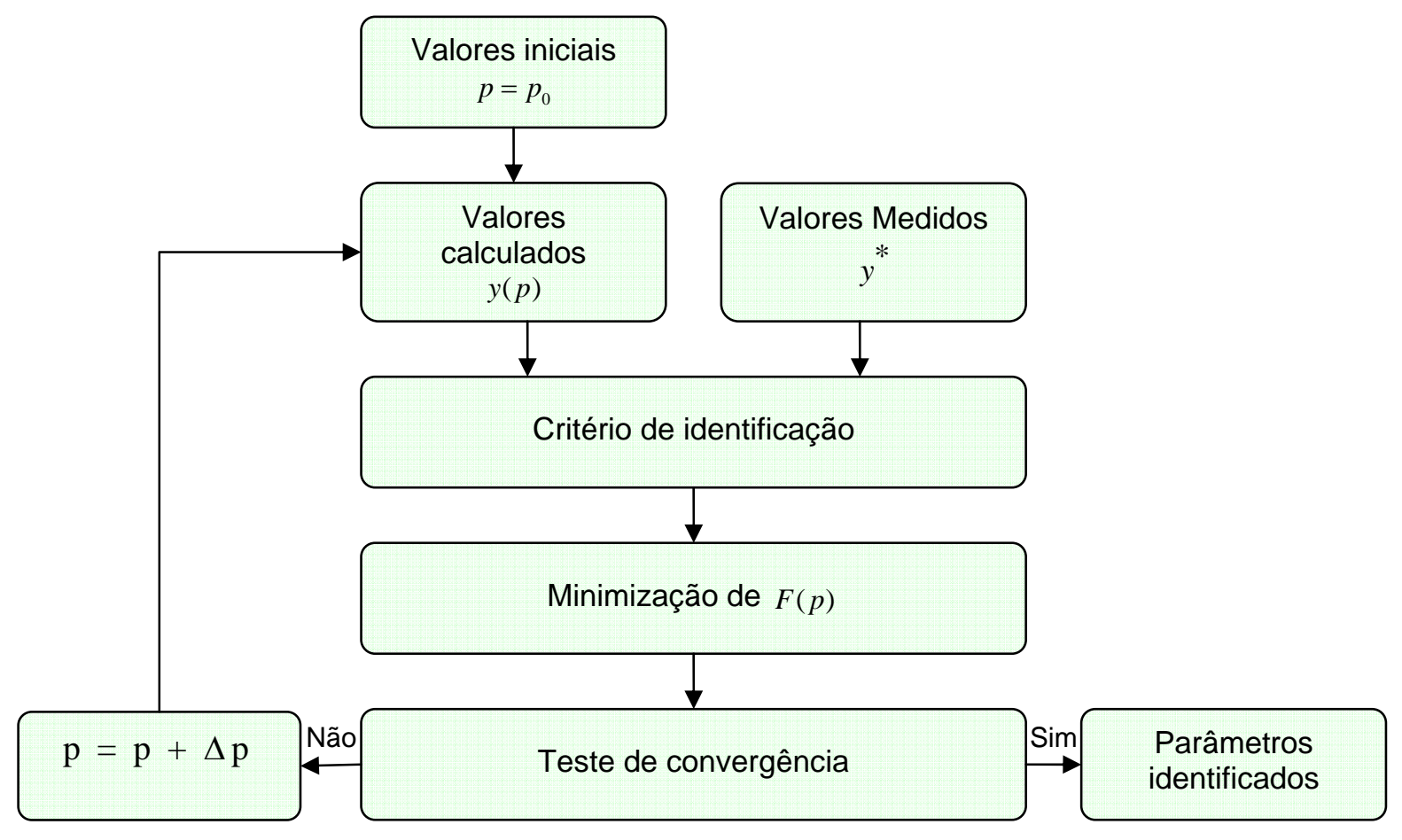

Figura 3.2. Processo Iterativo

A partir da Equação (3.1), a função objetivo que é caracterizada pelo critério dos mínimos quadrados pode ser reescrita na forma 


$$
F\left(p_{1}, \ldots, p_{n}\right)=\sum_{i=1}^{m} f_{i}^{2}\left(p_{1}, \ldots, p_{n}\right)
$$

onde

$$
f_{i}\left(p_{1}, \ldots, p_{n}\right)=y_{i}^{*}-y_{i}\left(p_{1}, \ldots, p_{n}\right)=\Delta y_{i}\left(p_{1}, \ldots, p_{n}\right),
$$

em que $\left(p_{1}, \ldots, p_{n}\right)$ são os $n$ parâmetros a serem identificados e $m$ é o número de medidas. Observa-se que $\Delta y_{i}\left(p_{1}, \ldots, p_{n}\right)$ representam as diferenças entre os valores medidos e os valores calculados. No que se segue adota-se a convenção $F\left(p_{j}\right)=F\left(p_{1}, \ldots, p_{n}\right)$.

O gradiente nulo da Equação (3.2) é a condição necessária de primeira ordem para o mínimo dessa função, ou seja,

$$
\frac{\partial F\left(p_{j}\right)}{\partial p_{k}}=\sum_{i=1}^{m} 2 f_{i}\left(p_{j}\right) \frac{\partial f_{i}\left(p_{j}\right)}{\partial p_{k}}=0 \quad(k=1, \ldots, n) .
$$

Portanto, é necessário determinar os parâmetros $\left(p_{1}, \ldots, p_{n}\right)$ para que as $n$ equações do sistema sejam satisfeitas:

$$
\sum_{i=1}^{m} f_{i}\left(p_{j}\right) \frac{\partial f_{i}\left(p_{j}\right)}{\partial p_{k}}=0
$$

Fazendo

$$
A_{i, k}\left(p_{j}\right)=-\frac{\partial f_{i}\left(p_{j}\right)}{\partial p_{k}}=\frac{\partial y_{i}\left(p_{j}\right)}{\partial p_{k}},
$$

em que A é a matriz sensibilidade da resposta do sistema de ordem $m \times n$, formada pelas derivadas parciais dos valores calculados em relação aos parâmetros a estimar, e é representada por:

$$
\mathbf{A}=\left[\begin{array}{ccc}
\frac{\partial y_{1}\left(p_{j}\right)}{\partial p_{1}} & \cdots & \frac{\partial y_{1}\left(p_{j}\right)}{\partial p_{n}} \\
\vdots & \ddots & \vdots \\
\frac{\partial y_{m}\left(p_{j}\right)}{\partial p_{1}} & \cdots & \frac{\partial y_{m}\left(p_{j}\right)}{\partial p_{n}}
\end{array}\right] .
$$


Então a Expressão (3.5) se reduz a

$$
\sum_{i=1}^{m} f_{i}\left(p_{j}\right) A_{i, k}\left(p_{j}\right)=0 \quad(k=1, \ldots, n) .
$$

\subsection{MÉTODO DE NEWTON-RAPHSON}

Após escolher o modelo matemático, definir o critério de identificação e o algoritmo de minimização é necessário aplicar um método para minimização da função objetivo.

Seja $\left(\bar{p}_{1}, \cdots, \bar{p}_{n}\right)$ a solução da Expressão (3.5) e $\left(p_{1}, \ldots, p_{n}\right)$ a solução obtida no passo anterior tal que $\bar{p}_{j}=p_{j}+\Delta p_{j}$. Assim, as $n$ equações podem ser escritas na forma

$$
\sum_{i=1}^{m} f_{i}\left(p_{j}+\Delta p_{j}\right) \frac{\partial f_{i}\left(p_{j}+\Delta p_{j}\right)}{\partial p_{k}}=0 .
$$

Desenvolvendo-se (3.9) em série de Taylor em torno de $p_{j}$ e desprezando-se os termos de ordem superior, obtém-se:

$$
\sum_{i=1}^{m} f_{i}\left(p_{j}\right) \frac{\partial f_{i}\left(p_{j}\right)}{\partial p_{k}}+\sum_{j=1}^{n} \frac{\partial}{\partial p_{j}}\left(\sum_{i=1}^{m} f_{i}\left(p_{j}\right) \frac{\partial f_{i}\left(p_{j}\right)}{\partial p_{k}}\right) \Delta p_{j}=0
$$

ou

$$
\begin{aligned}
& \sum_{i=1}^{m} f_{i}\left(p_{j}\right) \frac{\partial f_{i}\left(p_{j}\right)}{\partial p_{k}}+\sum_{j=1}^{n}\left(\sum_{i=1}^{m} \frac{\partial f_{i}\left(p_{j}\right)}{\partial p_{j}} \frac{\partial f_{i}\left(p_{j}\right)}{\partial p_{k}}\right) \Delta p_{j}+ \\
& \sum_{j=1}^{n}\left(\sum_{i=1}^{m} f_{i}\left(p_{j}\right) \frac{\partial^{2} f_{i}\left(p_{j}\right)}{\partial p_{k} \partial p_{j}}\right) \Delta p_{j}=0
\end{aligned}
$$


Definindo

$$
B_{i, k j}\left(p_{j}\right)=-\frac{\partial^{2} f_{i}\left(p_{j}\right)}{\partial p_{k} \partial p_{j}}=\frac{\partial^{2} y_{i}\left(p_{j}\right)}{\partial p_{k} \partial p_{j}}
$$

e empregando a definição de $\mathbf{A}$ e $\Delta y_{i}$, temos que a Equação (3.11) pode ser representada por

$$
\left(-\sum_{i=1}^{m} \Delta y_{i} A_{i, k}\right)+\sum_{j=1}^{n}\left[\left(\sum_{i=1}^{m} A_{i, j} A_{i, k}\right)-\left(\sum_{i=1}^{m} \Delta y_{i} B_{i, k j}\right)\right] \Delta p_{j}=0
$$

ou na forma matricial

$$
-\mathbf{A}^{\mathrm{T}} \Delta \mathbf{y}+\mathbf{H} \Delta \mathbf{p}=\mathbf{0}
$$

onde a matriz Hessiana, $\mathbf{H}$, de ordem $n \times n$, da função $F\left(p_{j}\right)$ é definida por

$$
H_{k j}=\left(\sum_{i=1}^{m} A_{i, j} A_{i, k}\right)-\left(\sum_{i=1}^{m} \Delta y_{i} B_{i, k j}\right)
$$

ou, matricialmente, por

$$
\mathbf{H}=\mathbf{H}^{1}+\mathbf{H}^{2} \text { onde } \mathbf{H}^{1}=\mathbf{A}^{\mathbf{T}} \mathbf{A}
$$

O vetor das diferenças entre os valores medidos e os calculados, $\Delta \mathbf{y}$, de ordem $m \times 1$, é descrito abaixo:

$$
\Delta \mathbf{y}=\left\{\begin{array}{c}
\Delta y_{1} \\
\vdots \\
\Delta y_{m}
\end{array}\right\}=\left\{\begin{array}{c}
y_{1}^{*}-y_{1}\left(p_{j}\right) \\
\vdots \\
y_{m}{ }^{*}-y_{m}\left(p_{j}\right)
\end{array}\right\} .
$$

O método de Newton-Raphson é um processo iterativo baseado na Equação (3.8), a qual se faz necessário fazer correções nas parcelas lineares, caracterizado na iteração $r$ por

$$
\left.p\right|_{r+1}=\left.p\right|_{r}+\left.\Delta p\right|_{r}
$$


com

$$
\left.\Delta p\right|_{r}=\left.\left.\left.H^{-1}\right|_{r} A^{T}\right|_{r} \Delta y\right|_{r}
$$

\subsection{MÉTODO DE GAUSS-NEWTON}

O método de Gauss-Newton é uma alteração no método de Newton-Raphson no qual se supõe que os incrementos $\Delta p_{j}$ sejam pequenos. Neste caso, a função objetivo pode ser aproximada por uma função quadrática no intervalo, e a matriz Hessiana (3.16), se reduz a:

$$
\mathbf{H} \approx \mathbf{A}^{\mathrm{T}} \mathbf{A} .
$$

Embora essa aproximação seja favorável com relação à praticidade nos cálculos, ela possui a desvantagem de poder apresentar mau condicionamento numérico na resolução do sistema de equações resultantes.

\subsection{MÉTODO DE LEVENBERG-MARQUARDT}

Para solucionar o problema de condicionamento numérico que pode ocorrer no método de Gauss-Newton, o método de Levenberg-Marquadt se diferencia basicamente pela inserção de uma matriz $\lambda \mathbf{I}$ em (3.20), ou seja,

$$
\mathbf{H} \approx \mathbf{A}^{\mathbf{T}} \mathbf{A}+\lambda \mathbf{I}
$$

onde $\lambda$ é um escalar positivo variável em cada interação e I é a matriz identidade.

Esse condicionamento numérico se dá por meio da introdução do termo $\lambda \mathbf{I}$, onde $\lambda$, no método de Levenberg-Marquardt, inicia-se com um valor alto e então se diminuí quando há um decréscimo nos valores da função objetivo ou aumenta-se em caso contrário. 
Caso a ordem de grandeza dos parâmetros seja diferente, é necessário que se normalize o problema. Isto é feito substituindo a matriz identidade da Equação (3.21) por uma matriz diagonal de ordem $n$ com os elementos iguais aos elementos da diagonal da matriz $\mathbf{A}^{\mathrm{T}} \mathbf{A}$.

O método que será utilizado para a minimização da função objetivo no decorrer deste trabalho é o de Levenberg-Marquardt juntamente com o critério dos mínimos quadrados para a identificação dos parâmetros pois, como se verifica em Horvath (2005), este algoritmo de otimização é o mais adequado para este problema. 


\title{
4. Algorítmos genÉticos
}

\author{
4.1. INTRODUÇÃO
}

Os Algoritmos Genéticos (AG's) pertencem a uma família de modelos computacionais inspirados na evolução. São métodos generalizados de busca e otimização que simulam os processos naturais de evolução, aplicando a idéia darwiniana de seleção dos mais aptos. Esta é uma área da inteligência artificial que vem crescendo rapidamente.

Os AG's foram inventados por John Holland na década de 60 e desenvolvido por ele, colegas e alunos da universidade de Michigan entre os anos de 1960 e 1970. Holland deu início à utilização dos algoritmos na resolução de problemas específicos, mas em especial, no estudo do fenômeno da adaptação como ocorre na natureza e no desenvolvimento de mecanismos da adaptação natural que pudessem ser implementados em sistemas computacionais. E em 1975, John Holland propôs os algoritmos genéticos em seu livro "Adaptation in Natural and Artificial Systems".

Classificado como método direto, o Algoritmo Genético é uma técnica considerada bastante versátil pelos seus usuários. Ele resulta de um mecanismo de procura, bastante robusto, num espaço complexo e descontínuo, que são bastante difíceis ou quase impossíveis de se resolver com os tradicionais métodos de cálculos. Sua diferença básica em relação às técnicas usuais de programação matemática é que a procura da solução se inicia em uma população de possíveis soluções e a partir desta busca-se uma nova população e se faz uma nova avaliação, até que o critério de parada seja satisfeito. Enquanto nas técnicas de programação matemática de otimização a procura é iniciada a partir de um único "indivíduo" (solução básica) e dela se determina à direção na qual se deve "caminhar" em busca do próximo 
indivíduo a solução ótima, caminho este que é dado a partir do cálculo de derivadas. Nos AG's não há essa necessidade.

De acordo com Vas (1999), as principais vantagens no uso dos Algoritmos Genéticos são as seguintes:

- São livres de derivadas em sua formulação;

- Podem ser utilizados em problemas de otimização contínuos ou discretos;

- Utilizam de operadores estocásticos em vez de regras determinísticas de procura para uma solução ótima (porém, não são procuras aleatórias no espaço de busca). Os AG's consideram alguns pontos no espaço de busca simultaneamente, e não apenas um único ponto, reduzindo, assim, a probabilidade de convergência para um mínimo local. Nas técnicas de programação matemática de busca, um único ponto é considerado, conduzindo muitas vezes a um mínimo local. Contudo, os AG's geram uma população de pontos (seqüências codificadas), testam cada ponto independentemente, e combinam características existentes nos pontos para formar uma nova população que contém pontos "melhorados". Assim, há uma busca global da solução.

\subsection{DEFINIÇÕES}

O conceito básico da seleção natural é que as condições ambientais selecionam uma determinada característica de um organismo que o ajuda na sobrevivência e reprodução desse organismo; em contrapartida os organismos que não possuem essas características podem morrer antes de se reproduzirem ou serem menos prolíficos que os organismos que apresentam a determinada característica. Desde que as condições da natureza não variem, ou permaneçam suficientemente similares, essas características continuam a se "adaptar" e elas tornar-se-ão mais comuns na população. 
Nesta seção serão introduzidas algumas terminologias da biologia que são utilizadas durante o decorrer deste trabalho. No contexto dos AG's, esses termos biológicos são usados de forma análoga aos termos reais da biologia, embora, sendo utilizada de forma mais simples do que acontece realmente.

Abaixo se encontram os termos empregados na descrição dos AG's e suas definições:

- Cromossomo: Para os AG's cada cromossomo (indivíduo) representa uma possível solução para o problema, ou seja, cada cromossomo destes representa as informações relativas às variáveis do problema.

- Gen ou Gene: Cada gene representa uma informação específica na cadeia do cromossomo.

- População: Grupo de organismos da mesma espécie, que nos AG's são os cromossomos, ou seja, o conjunto de soluções possíveis.

- Geração: Descendência ou iteração que o Algoritmo Genético executa.

- Operações Genéticas: Nos AG's representam as operações, por exemplo, cruzamento e mutação, que são realizadas em cada cromossomo.

- Espaço de Busca ou Região Viável: O espaço de busca se divide em duas regiões possíveis, aquela em que as soluções satisfazem a todas as restrições do problema, região viável, e a que não satisfaz todas as restrições, região inviável.

- Função Objetivo: É a função de um problema de otimização, ela é construída a partir dos parâmetros que envolvem o problema. Esta fornece uma medida da proximidade da solução em relação a um conjunto de parâmetros. Nos Algoritmos Genéticos ela fornece as informações numéricas de cada cromossomo na população. A função pode ser descrita na forma $F=f\left(p_{1}, \ldots, p_{n}\right)$, em que $\left(p_{1}, \ldots, p_{n}\right)$ representam as variáveis que se quer encontrar com a otimização de $F$. 


\subsubsection{Representação ou Codificação}

Nos AG's as variáveis de projeto a serem otimizadas devem ser representadas ou codificadas, de forma mais simples possível, contudo sem perder as características principais do problema.

Os cromossomos podem ter diversas representações ou codificações, tais como: binárias, números inteiros e números reais. A forma mais comum de representação das variáveis utilizada na maioria dos trabalhos é a codificação binária, onde cada cromossomo é um vetor composto por zeros e uns, com cada bit representando um gene. A Tabela 4.1 ilustra a representação binária utilizada.

Tabela 4.1. Representação binária de cromossomos

\begin{tabular}{cc}
\hline Cromossomos & Representação \\
\hline Pai 1 & 1101100100110110 \\
\hline Pai 2 & 1101111000011110 \\
\hline
\end{tabular}

\subsubsection{Operadores Genéticos}

O princípio básico dos operadores genéticos é transformar a população através de sucessivas gerações, estendendo a busca até chegar a um resultado satisfatório. Os operadores genéticos são responsáveis pela variação das populações por meio de sucessivas gerações e são extremamente necessários para que esta se diversifique e mantenha as características de adaptação adquiridas pelas gerações anteriores. 


\subsubsection{Cruzamento}

O cruzamento é o operador responsável pela recombinação de características dos pais durante a reprodução, permitindo que as próximas gerações herdem essas características. Também conhecido como operador crossover, este pode ser utilizado das seguintes maneiras:

- Cruzamento de um ponto - um ponto de cruzamento é escolhido e a partir dele as informações dos cromossomos "pais" são trocadas. O cruzamento de um ponto é exemplificado na Tabela 4.2.

Tabela 4.2. Cruzamento de um ponto

\begin{tabular}{|c|c|}
\hline Cromossomos & Representação \\
\hline Pai 1 & 11011 | 00100110110 \\
\hline Pai 2 & $11011 \mid 11000011110$ \\
\hline Filho 1 & $11011 \mid 11000011110$ \\
\hline Filho 2 & $11011 \mid 00100110110$ \\
\hline
\end{tabular}

- Cruzamento multiponto - é uma generalização do cruzamento de um ponto, onde muitos pontos de cruzamentos podem ser utilizados. A Tabela 4.3 ilustra a operação de cruzamento multiponto.

Tabela 4.3. Cruzamento multiponto

\begin{tabular}{|c|c|}
\hline Cromossomos & Representação \\
\hline Pai 1 & 11011001001 | 10110 \\
\hline Pai 2 & $11011|110000| 11110$ \\
\hline Filho 1 & $11011|110000| 10110$ \\
\hline Filho 2 & $11011001001 \mid 11110$ \\
\hline
\end{tabular}


- Cruzamento uniforme - não utiliza pontos de cruzamento, mas é determinado por meio de um parâmetro global, ou uma "máscara", que determina a probabilidade de cada variável a ser herdada de cada pai. Se o primeiro bit da máscara possui o valor 1 , então o primeiro bit do Pai 1 (ou cromossomo 1) é copiado para o primeiro bit da Filho 1. Caso contrário, o primeiro bit do Pai 2 é copiado para o primeiro bit da Filho 1 (ou descendência 1). O processo se repete para os bits restantes da Filho 1. Na geração da Filho 2 o procedimento é invertido, ou seja, se o bit da máscara é 1, então será copiado o bit do Pai 2. Se o bit for igual a 0 , então será copiado o bit do Pai 1 . Este processo é apresentado na Tabela 4.4.

Tabela 4.4. Cruzamento uniforme

\begin{tabular}{cc}
\hline Máscara & $\mathbf{1 1 0 0 1 1 0 1 1 0 0 1 0 1 0 1}$ \\
\hline Pai 1 & 1101100100110110 \\
\hline Filho 1 & 1101101100011110 \\
\hline Pai 2 & 1101111000011110 \\
\hline
\end{tabular}

\subsubsection{Mutação}

A mutação é um operador genético indispensável à manutenção da variedade genética da população. Ela tem a finalidade de prevenir que as soluções do problema dessa população caiam em um ponto ótimo local. A operação de mutação muda aleatoriamente a descendência criada pelo cruzamento. No caso de uma codificação binária, muda-se aleatoriamente alguns bits escolhidos de 1 para 0 , ou de 0 para 1. A mutação é ilustrada na Tabela 4.5. 
Tabela 4.5. Mutação

\begin{tabular}{lll}
\hline \multirow{2}{*}{ Descendência } & Antes da Mutação & 1101101100011110 \\
\cline { 2 - 3 } & Depois da Mutação & 1100101101011110 \\
\hline
\end{tabular}

\subsection{PARÂMETROS DE INFLUENNCIA NOS ALGORITMOS GENÉTICOS}

A escolha dos parâmetros de influência é essencial no desempenho de busca em um AG. Contudo, não existe uma regra para se obter uma maior eficiência, uma vez que a escolha desses parâmetros depende do problema a ser resolvido.

Os principais parâmetros de influência em um Algoritmo Genético são: Tamanho da População; Taxa ou Probabilidade de Cruzamento e Taxa ou Probabilidade de Mutação.

O tamanho da população e o número de gerações dependem da complexidade do problema de otimização e devem ser determinados experimentalmente. Se esta população for grande haverá uma maior diversidade, porém com um maior custo computacional na avaliação da função aptidão. Por outro lado, com uma população pequena a eficiência do AG pode cair, pois desta maneira a população escolhida representaria apenas uma pequena cobertura do espaço de busca.

No entanto, deve ser observado que o tamanho da população e o número de gerações definem diretamente o tamanho do espaço de busca a ser coberto. Existem estudos que utilizam um AG como método de otimização para a escolha dos parâmetros de outro $A G$, devido à importância da escolha correta destes parâmetros.

A taxa de cruzamento indica a probabilidade de ocorrência do cruzamento entre os indivíduos na população. Quanto maior for esta taxa, mais rapidamente novas 
estruturas serão introduzidas na população. Mas se esta for muito alta, estruturas com boas aptidões poderão ser retiradas mais rapidamente da população, ocorrendo perda de estruturas de alta aptidão. Com um valor baixo, o algoritmo pode tornar-se muito lento em sua convergência.

Segundo Castro (2001), a taxa de cruzamento comumente varia entre 0,5 e 0,95, mas que apenas indicam uma ordem de grandeza, pois existem inúmeros tipos possíveis de cruzamentos.

A taxa de mutação é a probabilidade em que haverá a mutação na estrutura do cromossomo nas populações das diversas gerações e é empregada para fornecer novas informações dentro das populações. Uma baixa taxa de mutação previne que uma dada posição fique estagnada em um valor, além de possibilitar que se chegue a qualquer ponto do espaço de busca. Com uma taxa muito alta a busca se torna essencialmente aleatória.

Assim, a determinação de um conjunto de valores otimizado para estes parâmetros dependerá da realização de um grande número de experimentos e testes. $\mathrm{Na}$ maioria da literatura os valores encontrados estão na faixa de 60 a 65\% para a probabilidade de cruzamento e entre 0,1 e 5\% para a probabilidade de mutação.

\subsection{ESTRUTURA DOS ALGORITMOS GENÉTICOS}

No método dos Algoritmos Genéticos as soluções encontradas para os problemas são consideradas como soluções "boas" e aproximadas, já que na maioria dos problemas não se sabe qual é a sua solução exata.

O AG começa com uma população que é um conjunto de possíveis soluções (representadas pelos cromossomos). Em seguida, as soluções dessa população são avaliadas e usadas para gerar uma nova população. Por sua vez essa nova população gerada terá soluções melhores que a anterior e novamente será avaliada. 
Silva (2001) descreve esse processo genérico no algoritmo a seguir:

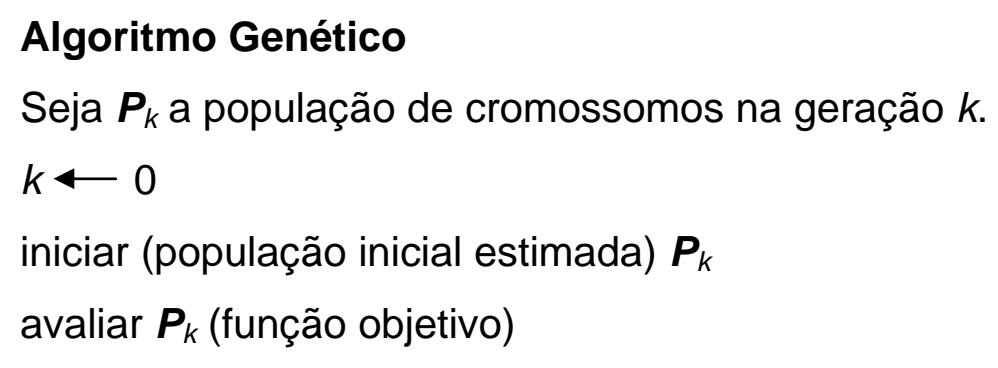

Enquanto o critério de parada não for satisfeito faça

$k \leftarrow k+1$

aplicar seleção em $\boldsymbol{P}_{k}$ a partir de $\boldsymbol{P}_{k-1}$

aplicar cruzamento sobre $\boldsymbol{P}_{k}$

aplicar mutação sobre $\boldsymbol{P}_{k}$

avaliar $\boldsymbol{P}_{k}$ (função objetivo)

Fim

Os mais aptos podem sofrer modificações em suas características principais por meio de operadores de cruzamentos e mutações, gerando descendentes para a próxima geração. Deste modo, o processo é realizado até que uma solução satisfatória seja encontrada.

Essa solução satisfatória seria aquela solução encontrada ao fim do critério de parada. Segundo Silva (2001), os critérios de parada podem ser quando:

- Atingir determinado valor da função objetivo;

- Um número de gerações ou avaliações for alcançado pelo algoritmo genético;

- Não ocorrer um melhoramento expressivo na solução de maior aptidão, ou seja, ocorrer uma "convergência" por meio de um determinado número de avaliações. 


\section{MODELO EXPERIMENTAL}

\subsection{MODELO ANALISADO EXPERIMENTALMENTE}

O modelo estudado é o de uma viga em concreto armado e protendido simplesmente apoiada, com comprimento total de 4,11m (3,96m entre apoios), e seção transversal de $15 \mathrm{~cm}$ de base por $20 \mathrm{~cm}$ de altura (Figura 5.1) com armadura longitudinal simétrica ( $4 \phi 12 \mathrm{~mm}$ ) de aço com valor característico de resistência de escoamento, $f_{y k}$, de 500MPa e a armadura transversal formada por estribos de $\phi 6 \mathrm{~mm}$, a cada $10 \mathrm{~cm}$, de mesma classe do aço da armadura longitudinal.

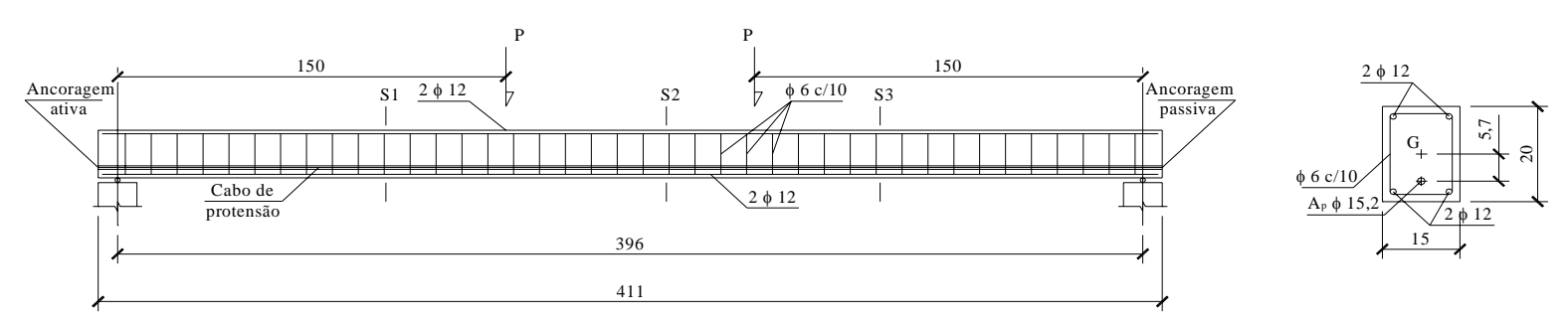

Figura 5.1. Viga de concreto armado e protendido (medidas em $\mathrm{cm}$ )

Para a protensão foi utilizada uma cordoalha de sete fios com seção transversal de $1,40 \mathrm{~cm}^{2}$ e tensão característica, $f_{p t k}$, de $1857 \mathrm{MPa}$.

$\mathrm{O}$ concreto utilizado tem resistência característica à compressão $\left(f_{c k}\right)$ de $40 \mathrm{MPa}$. A viga objeto de análise foi ensaiada no LABEST - Laboratório da Tecnologia do Betão e do Comportamento Estrutural do Departamento de Engenharia Civil da Faculdade de Engenharia da Universidade do Porto. Os dados obtidos nos ensaios 
foram gentilmente cedidos para o desenvolvimento desse trabalho. Observa-se que as informações gerais sobre a viga estão apresentadas em SOUZA et al. (2002).

A viga está sujeita ao peso próprio, à protensão induzida por um cabo não aderente retilíneo com $5,7 \mathrm{~cm}$ de excentricidade em relação ao eixo da seção e a duas forças concentradas, $P$, aplicadas a 1,50 $\mathrm{m}$ dos apoios. A Tabela 5.1 resume o valor das ações aplicadas à viga.

Tabela 5.1. Ações na viga

\begin{tabular}{cc}
\hline Ação & Valor \\
\hline Peso próprio & $G=0,75 \mathrm{kN} / \mathrm{m}$ \\
\hline Protensão excêntrica & $P_{m 0}=172 \mathrm{kN}$ \\
\hline Ação de longa duração & $P=8,38 \mathrm{kN}$ \\
\hline
\end{tabular}

\subsection{MONITORAMENTO DO EXPERIMENTO}

Foram instrumentados a viga em concreto armado (Figura 5.2) e dois prismas (Figura 5.5) com extensômetros de resistência elétrica auto-compensados ao efeito da temperatura para que se pudessem obter registros contínuos das deformações. 


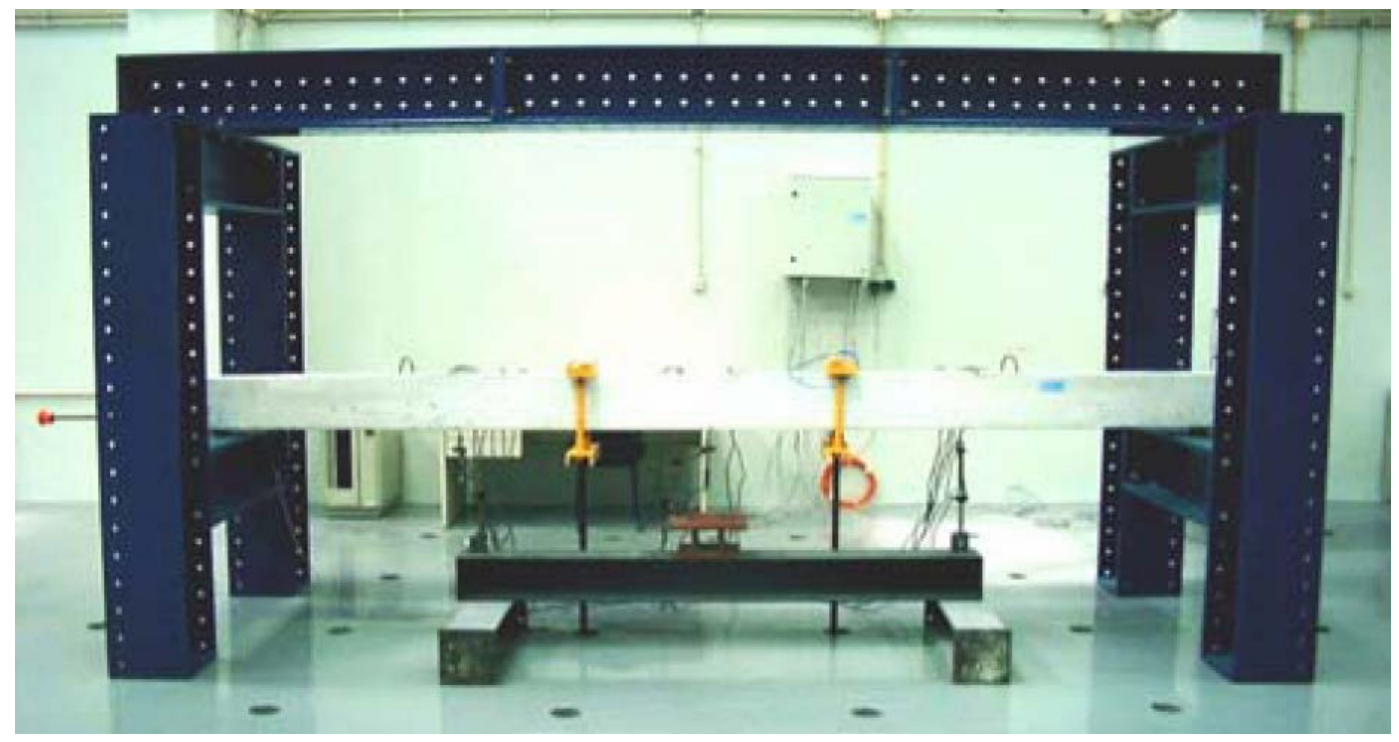

Figura 5.2. Viga em concreto armado e protendido

(SOUSA; FÉLIX; FIGUEIRAS, 2002)

Os extensômetros estavam dispostos nas seções S1, S2 e S3. Em cada seção foram instalados quatro extensômetros fixados no aço e dois de embeber no concreto conforme se mostra na Figura 5.3.

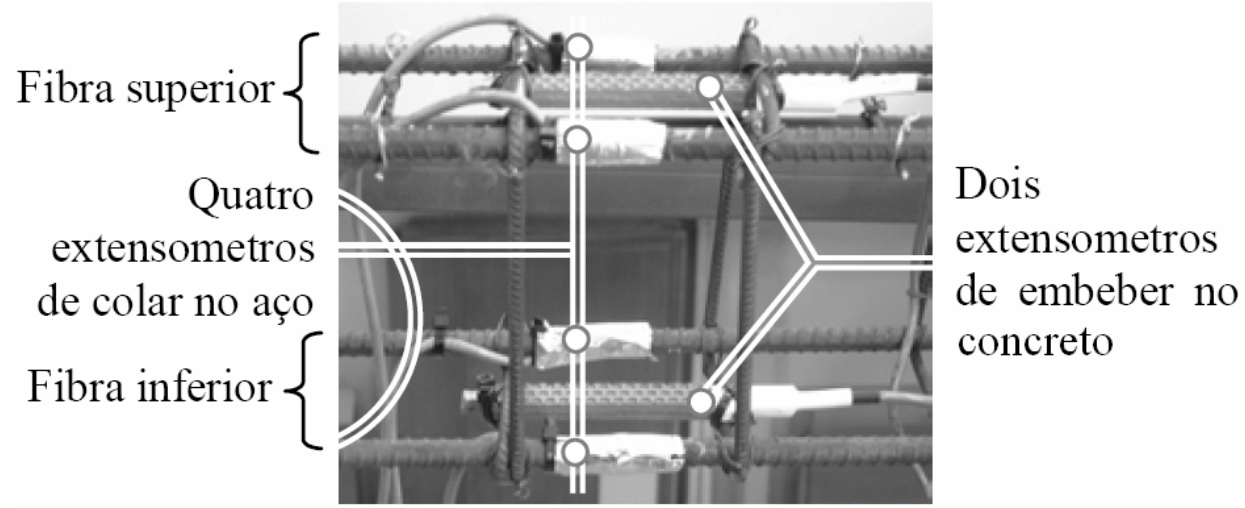

Figura 5.3. Seção monitorada

(SOUSA; FÉLIX; FIGUEIRAS, 2002)

A viga também foi instrumentada por uma célula de carga (Figura 5.4) na ancoragem ativa para medir a evolução da força de protensão. E no laboratório foi instalado um sensor de temperatura para a medição da temperatura ambiente. 


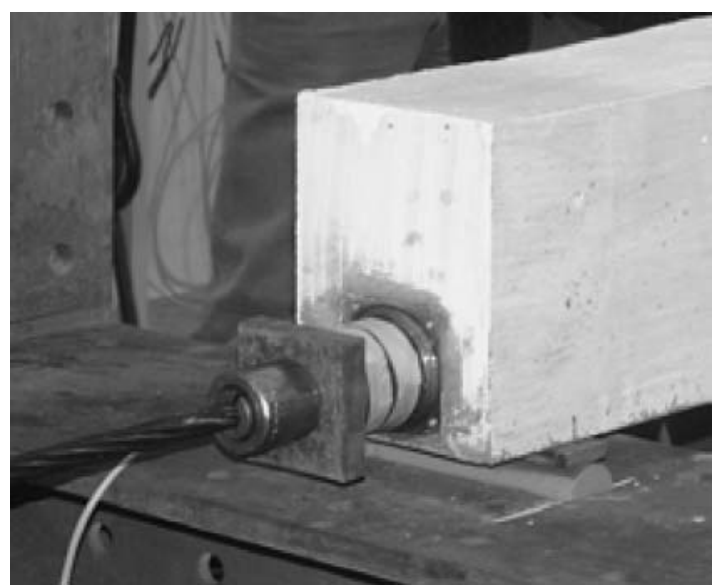

Figura 5.4. Célula de carga

(SOUSA; FÉLIX; FIGUEIRAS, 2002)

Os prismas da Figura 5.5 foram concretados com o mesmo concreto e no mesmo dia da viga, um para monitorar a retração (PR) e o outro para a fluência (PF), e dimensões de $15 \mathrm{~cm} \times 15 \mathrm{~cm} \times 55 \mathrm{~cm}$.

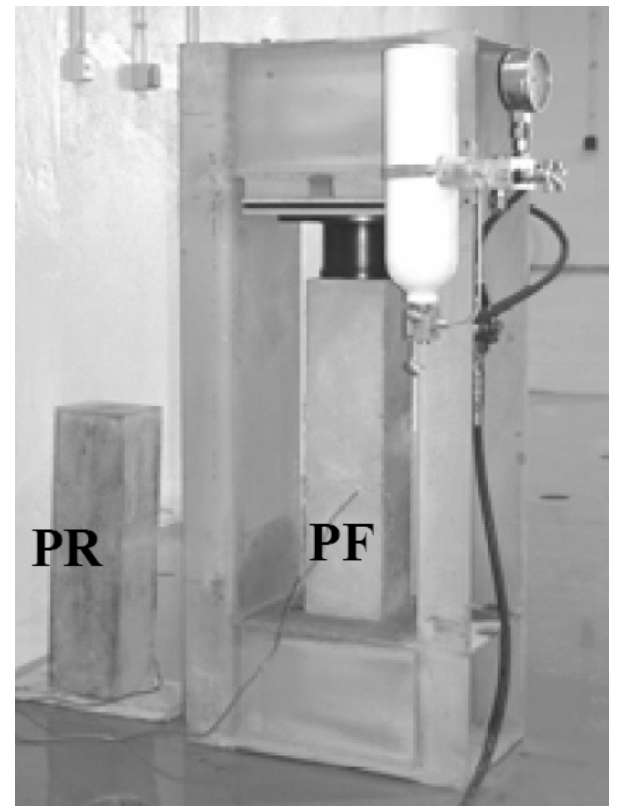

Figura 5.5. Prismas

(SOUSA; FÉLIX; FIGUEIRAS, 2002)

Todo este equipamento é ligado a um sistema de aquisição, que registra e armazena as leituras efetuadas. A viga descrita (Figura 5.2) foi concretada no LABEST-FEUP em 23 de novembro de 2001 e foi sujeita a um histórico de 
carregamento que envolve a operação de protensão, carga e descarga com ações de longa duração. A Tabela 5.2 resume as operações cronologicamente.

Tabela 5.2. Histórico de carregamento

\begin{tabular}{ccc}
\hline Ação & Data & $t_{0 i}$ (dias) \\
\hline Aplicação da protensão, $t_{01}$ & $18 / 12 / 2001$ & 25 \\
\hline Aplicação da ação de longa duração, $t_{02}$ & $18 / 02 / 2002$ & 87 \\
\hline Descarga da ação de longa duração, $t_{03}$ & $14 / 06 / 2002$ & 203 \\
\hline $2^{\mathrm{a}}$ aplicação da ação de longa duração, $t_{04}$ & $20 / 06 / 2002$ & 209 \\
\hline
\end{tabular}

\subsection{RESULTADOS EXPERIMENTAIS}

As Figuras abaixo apresentam as deformações lineares da viga, medidas pelos extensômetros de embeber no concreto que foram instalados em fibras superiores e inferiores das secções $S_{1}, S_{2}$ e $S_{3}$.

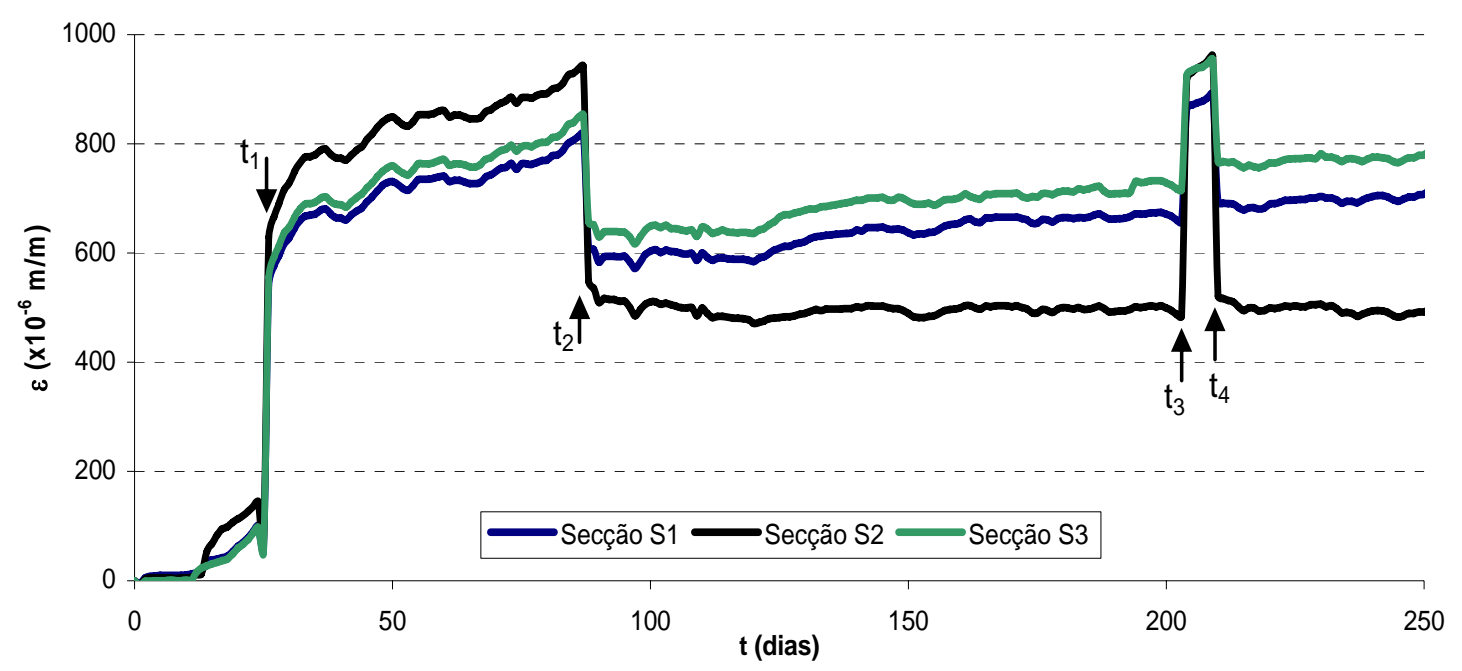

Figura 5.6. Deformações lineares específicas medidas nas fibras superiores 


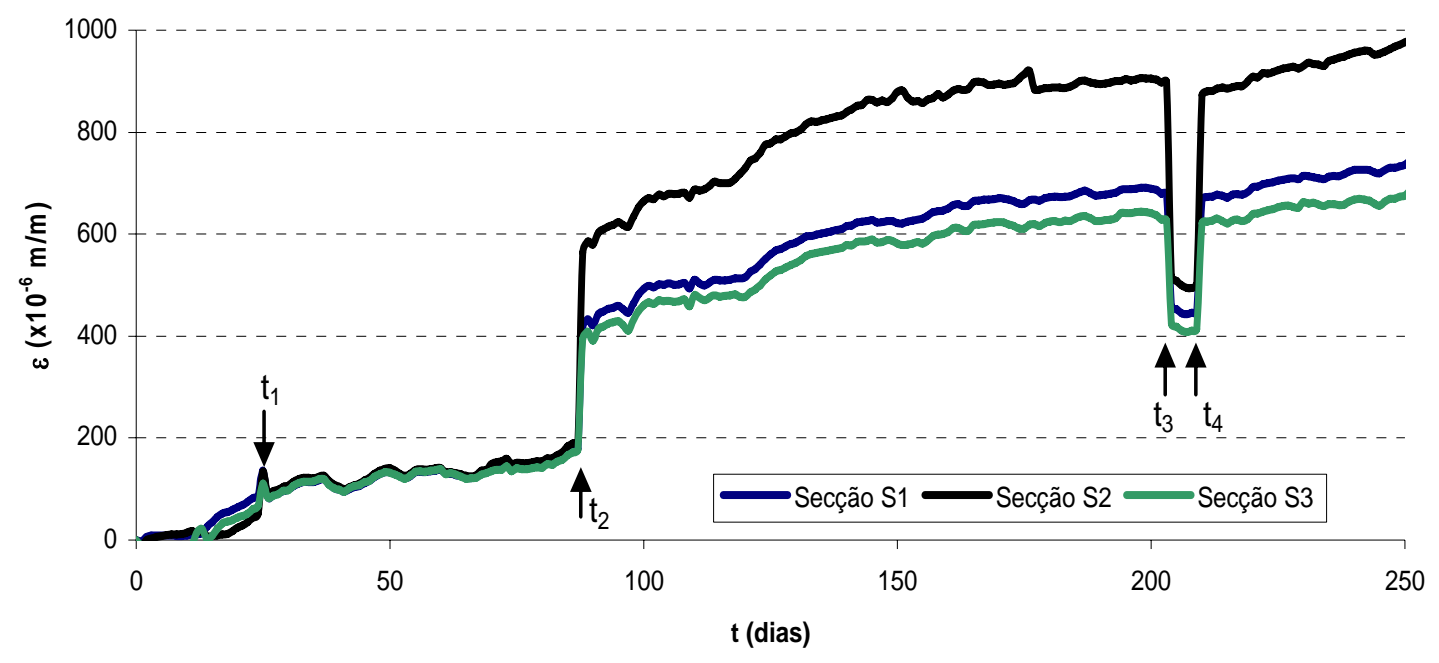

Figura 5.7. Deformações lineares específicas medidas nas fibras inferiores 


\section{RESULTADOS}

\subsection{INTRODUÇÃO}

A deformação linear específica total do concreto, já retirada à parcela do efeito de temperatura, é expressa pela Equação (2.1) e pode ser posta na forma:

$$
\varepsilon_{c}\left(t, t_{0}\right)=\varepsilon_{c i}\left(t_{0}\right)+\varepsilon_{c c}\left(t, t_{0}\right)+\varepsilon_{c s}(t)=\varepsilon_{c \sigma}\left(t, t_{0}\right)+\varepsilon_{c s}(t),
$$

onde, $\varepsilon_{c \sigma}\left(t, t_{0}\right)$ representa a soma das deformações lineares específicas instantânea no instante $t_{0}$ e por fluência em um instante $t>t_{0}$ e que pode ser apresentada na forma:

$$
\varepsilon_{c \sigma}\left(t, t_{0}\right)=\sigma_{c}\left(t_{0}\right) J\left(t, t_{0}\right)
$$

onde, $\sigma_{c}\left(t_{0}\right)$ é a tensão constante aplicada no instante $t_{0}$.

Apresentam-se como resultados as curvas de funções de fluência, $J\left(t, t_{0_{i}}\right)$, correspondentes aos diversos instantes de carregamentos do experimento devidamente ajustadas pelos modelos de Boltzmann e CEB-Santos, e comparadas com a do CEB.

As curvas do CEB são obtidas diretamente da aplicação desse código às condições da viga. As curvas correspondentes às deformações lineares específicas medidas na seção $S_{2}$ são obtidas considerando-se as parcelas dos alongamentos $\varepsilon_{c \sigma}\left(t, t_{o_{i}}\right)$, ou seja, parcela da deformação linear específica total subtraída da parcela de retração, $\varepsilon_{c s}(t)$, obtida pelo prisma de retração, em seguida divide-se esses valores pelas correspondentes tensões em $t_{o_{i}}$. 
Para a obtenção das curvas de fluência CEB-Santos aplica-se a técnica da retroanálise e o método dos AG's na obtenção dos parâmetros $C_{3}$ e $C_{4}$. E, finalmente, aplicando-se a retroanálise para a obtenção dos parâmetros $E_{1}$ e $\eta_{1}$ das curvas de fluência referente ao modelo de Boltzmann.

\subsection{PARAMETROS IDENTIFICADOS}

Nesta seção são apresentados na forma numérica os valores encontrados para os parâmetros, assim como os valores da função objetivo para cada par de coeficientes ajustados.

Foi desenvolvido um programa utilizando a linguagem em MATLAB, onde se empregou a técnica de retroanálise na identificação dos parâmetros $C_{3}$ e $C_{4}$ do modelo CEB-Santos e, $E_{1}$ e $\eta_{1}$ do modelo de Boltzmann.

No que diz respeito à identificação dos parâmetros por AG foi utilizada uma ferramenta disponível no toolbox do MATLAB, ver Figura 6.1.

Nessa ferramenta de resolução é necessário indicar, como dados de entrada, a função a ser minimizada e o número de variáveis do problema. Também se torna importante definir algumas opções como: população, tipo de seleção e de reprodução, cruzamento, mutação e os critérios de parada.

Utilizando os recursos do software em questão foi desenvolvida uma interface gráfica para dados de entrada do modelo CEB e CEB-Santos. Essa interface se tornou possível utilizando um ambiente desenvolvido que acompanha o MATLAB, o GUIDE (Graphical User Inteface Development Environment), e que é mostrada na Figura 6.2. 


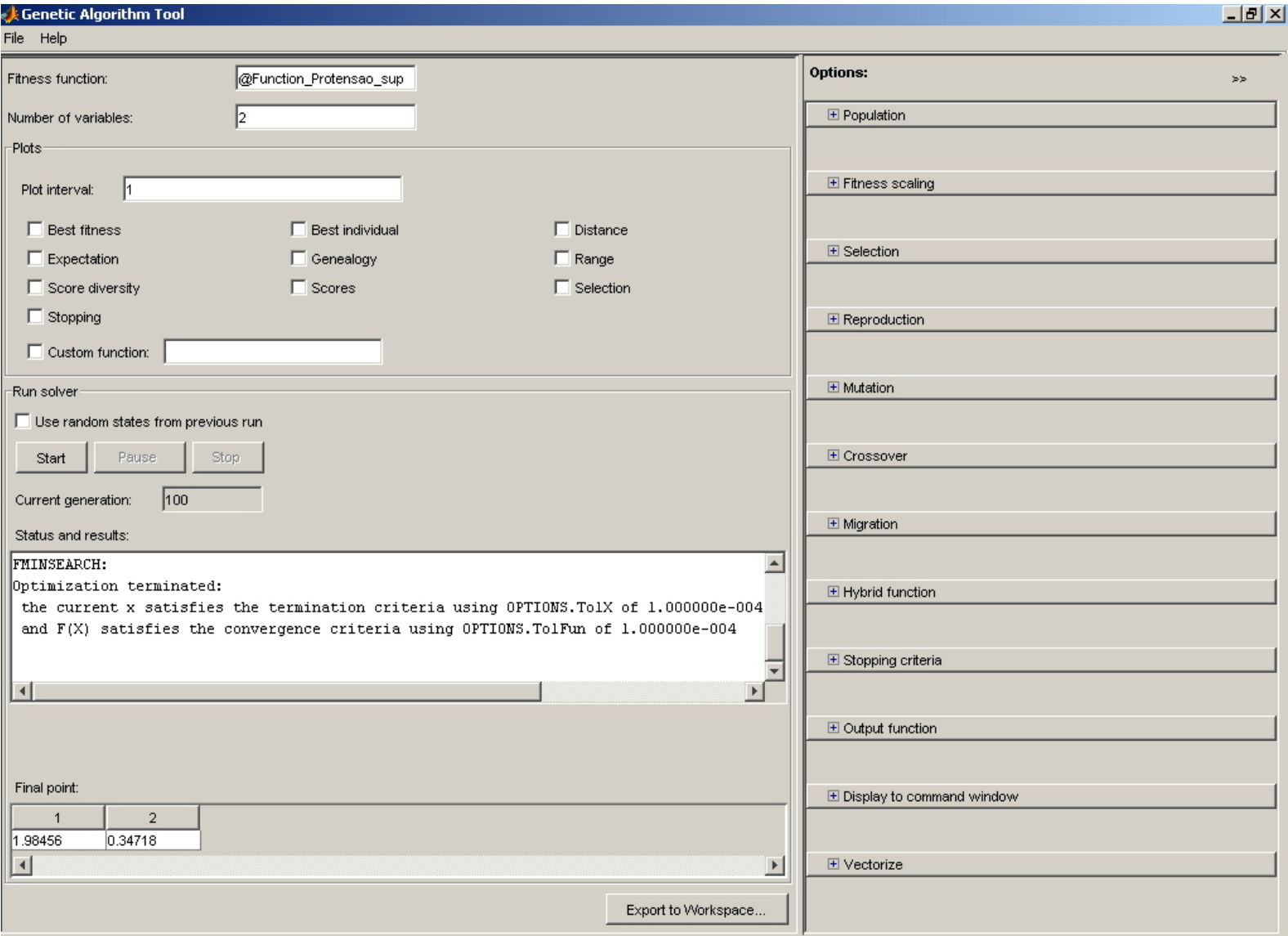

Figura 6.1. Ferramenta do MATLAB para resolução de problemas via AG's

Parametros

Caracteristicas do Concreto

\begin{tabular}{cc}
\cline { 2 - 2 } Fck & 41.79 \\
\cline { 2 - 2 } Fcm0 & 10 \\
\cline { 2 - 2 } Fcm & 49.79 \\
\cline { 2 - 2 } deltaf & 8 \\
\hline Es & 20000 \\
\hline Ec0 & 21500 \\
\hline$s$ & 0.38
\end{tabular}

$\mathrm{MPa}$

$\mathrm{MPa}$

$\mathrm{MPa}$

$\mathrm{MPa}$

$\mathrm{MPa}$

$\mathrm{MPa}$

$s \quad 0.38$

Fiuencia

alfa

h $\longdiv { 8 . 5 7 1 4 3 }$

u 70

$\mathrm{RH} \quad 60$

Retracao

Bsc 4

$\mathrm{cm}$

$\mathrm{cm}$

$\%$
Parametros do Carregamento
Seçoes: Aço e Concreto

d $\longdiv { 1 . 2 } \mathrm { cm }$

As $\longdiv { 4 . 5 2 3 8 9 } \mathrm { cm } 2$

Ap $\longdiv { 1 . 8 5 7 } \mathrm { cm } 2$

$\mathrm { h } \longdiv { 2 0 } \mathrm { cm } 2$

b $15 \mathrm{~cm} 2$

Ac $\longdiv { 3 0 0 } \mathrm { cm } 2$
Calcular

Protensao (Momento)

S1 $\longdiv { - 9 . 8 0 4 } \mathrm { kNm }$

S2 $\longdiv { - 9 . 8 0 4 } \mathrm { kNm }$

Protensao (Normal)

S1, 2, S3 $\longdiv { - 1 7 2 } \quad \mathrm { kN }$

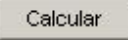

S3 $\longdiv { - 9 . 8 0 4 } \mathrm { kNm }$

Figura 6.2. Interface gráfica: Parâmetros de entrada

Idades do Carregamento

\begin{tabular}{c|c}
\cline { 2 - 2 } Protensao & 25 \\
\cline { 2 - 2 } Carga1 & 87 \\
\cline { 2 - 2 } Descarga & 203 \\
\cline { 2 - 2 } Carga2 & 209
\end{tabular}

Peso Proprio (Momento)

S1 $1.136 \mathrm{kNm}$

S2 1.463

S3 $\longdiv { 1 . 1 2 1 }$ kNm

Carga Permanente (Momento)

\begin{tabular}{l|cl}
\cline { 2 - 2 }$S 1$ & 8.682 & $\mathrm{kNm}$ \\
$\mathrm{S} 2$ & 12.570 & $\mathrm{kNm}$ \\
\cline { 2 - 2 } $\mathrm{S} 3$ & 8.506 & $\mathrm{kNm}$
\end{tabular}

Modulo de Elasticidade Ecio

Eci Prot $34.34 \quad$ GPa

Eci Carga1 $38.85 \quad \mathrm{GPa}$

Eci Descarga $40.97 \quad$ GPa

Eci Carga2 $\longdiv { 4 1 . 0 4 }$ GPa 
Apresentam-se na Tabela 6.1 os valores encontrados para os parâmetros $C_{3}$ e $C_{4}$, e os valores da função objetivo para cada par de parâmetros em cada instante de carregamento e fibra solicitada.

Tabela 6.1 - Valores de $C_{3}, C_{4}$ e da função objetivo $F$.

\begin{tabular}{cccccccc}
\hline & \multicolumn{4}{c}{ Levenberg Marquardt } & \multicolumn{2}{c}{ Algoritmos Genéticos } \\
\hline \multirow{2}{*}{ Carregamento } & \multirow{2}{*}{ Fibras } & $C_{3}$ & $C_{4}$ & $F\left(\times 10^{-24}\right)$ & $C_{3}$ & $C_{4}$ & $F\left(\times 10^{-24}\right)$ \\
\hline \multirow{2}{*}{ Protensão } & Superior & 0,361 & 0,519 & 424,3 & 0,361 & 0,519 & 448,8 \\
\cline { 2 - 8 } & Inferior & 0,663 & 0,659 & 35,6 & 0,663 & 0,659 & 43,8 \\
\hline \multirow{2}{*}{$\mathbf{1}^{\text {a Aplicação }}$} & Superior & 1,147 & 0,947 & 336,8 & 1,147 & 0,947 & 340 \\
\cline { 2 - 8 } & Inferior & 5,744 & 0,464 & 730,6 & 5,744 & 0,464 & 2850 \\
\hline \multirow{2}{*}{ Descarga } & Superior & 8,708 & 0,252 & 41,9 & 8,708 & 0,252 & 523,2 \\
\cline { 2 - 8 } & Inferior & 0,703 & 0,812 & 0,04 & 0,703 & 0,812 & 0,20 \\
\hline \multirow{2}{*}{$\mathbf{2}^{\text {a Aplicação }}$} & Superior & 0,753 & 0,564 & 12,1 & 0,753 & 0,564 & 12,5 \\
\cline { 2 - 8 } & Inferior & 5,458 & 0,181 & 104,7 & 5,458 & 0,181 & 5130 \\
\hline
\end{tabular}

Pode-se verificar na Tabela 6.1 que os valores encontrados para os parâmetros $C_{3} \mathrm{e}$ $\mathrm{C}_{4}$ do modelo CEB-Santos para o ajuste por retroanálise e por Algoritmos Genéticos foram idênticos. E isso se deve ao "bom" comportamento da função objetivo para as diferentes fases de carregamento.

A Figura 6.3 representa de forma qualitativa as funções objetivo para o modelo do CEB-Santos, na retroanálise e nos AG's, a qual mostra o bom comportamento da função, ou seja, com um mínimo global bem definido.

A Tabela 6.2 exibe os parâmetros que ajustam as curvas de funções de fluência em cada instante de carregamento e em cada fibra para o modelo reológico de três parâmetros de Boltzmann. Os coeficientes, $E_{1}$ e $\eta_{1}$, foram encontrados a partir da aplicação da técnica de retroanálise e $E_{0}$ identificado diretamente a partir do valor de deformação linear específica instantânea, ou seja, dividindo-se o acréscimo de tensão pelo acréscimo de deformação no instante aplicação do carregamento. 


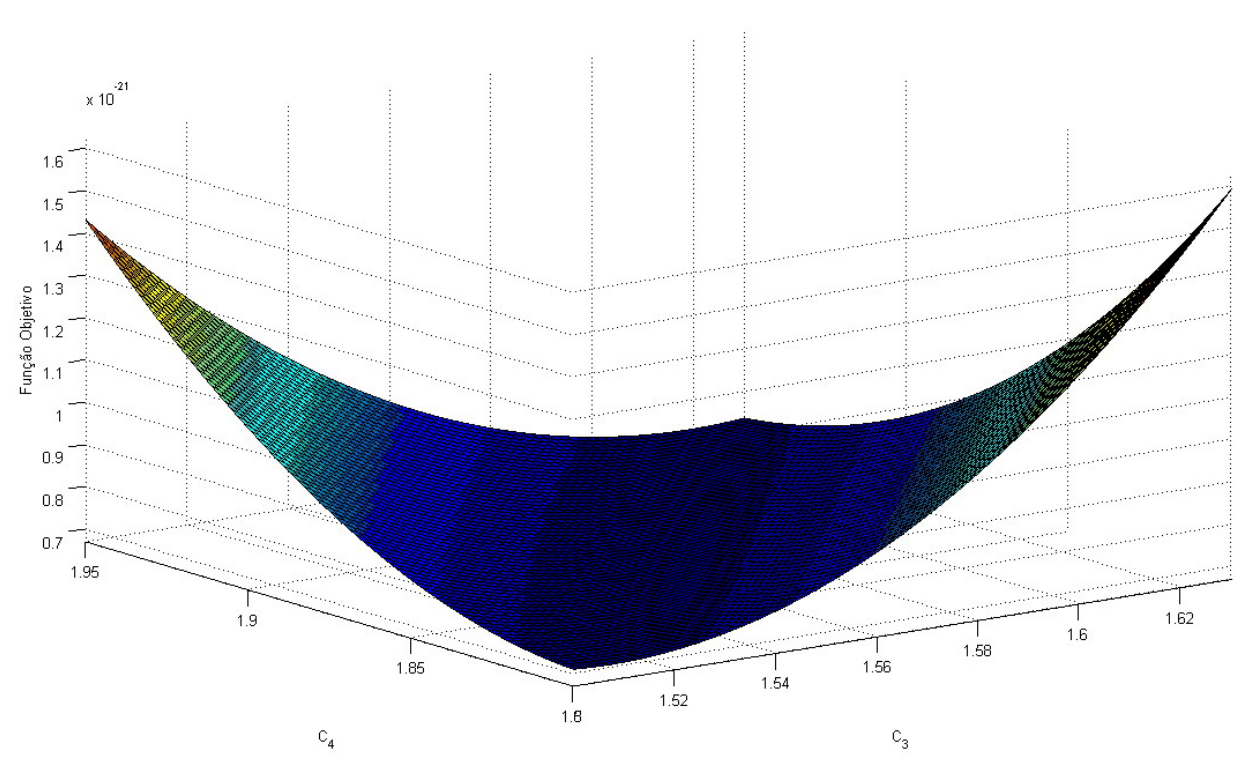

Figura 6.3. Função Objetivo

Tabela 6.2 - Valores de $E_{0}$, $E_{1}$ e $\eta_{1}$ para o modelo de Boltzmann.

\begin{tabular}{clccc}
\hline \multicolumn{5}{c}{ Modelo de Boltzmann } \\
\hline \multirow{2}{*}{ Carregamento } & Fibras & $E_{0}(G P a)$ & $E_{1}(G P a)$ & $\eta_{1}(G P a)$ \\
\hline \multirow{2}{*}{ Protensão } & Superior & 54 & 102 & 758 \\
\cline { 2 - 5 } & Inferior & 25 & 72 & 81300 \\
\hline \multirow{2}{*}{$\mathbf{1}^{\text {a Aplicação }}$} & Superior & 30 & 41 & 1300 \\
\cline { 2 - 5 } & Inferior & 27 & 11 & 455 \\
\hline \multirow{2}{*}{ Descarga } & Superior & 28 & --- & --- \\
\cline { 2 - 5 } & Inferior & 25 & --- & --- \\
\hline \multirow{2}{*}{$2^{a}$ Aplicação } & Superior & 29 & 61 & 4020 \\
\cline { 2 - 5 } & Inferior & 24 & 32 & 640 \\
\hline
\end{tabular}

Verificam-se na Tabela 6.2 que os valores para o módulo de elasticidade $\left(E_{0}\right)$ no instante de aplicação do carregamento são valores razoáveis, com exceção do valor encontrado para a fibra superior no instante de aplicação da protensão que foi destoante dos demais valores. No entanto, os demais valores também apresentam variação e isso se deve às perturbações nas medidas que foram realizadas nos instantes de carregamento. 


\subsection{RESULTADOS EM GRÁFICOS}

A fim de simplificar, ao invés de se referir às curvas ajustadas com parâmetros identificados por retroanálise ou por Algoritmo Genético será apenas mencionado que a curva é ajustada por retroanálise ou por Algoritmo Genético.

Nesta seção são apresentadas as curvas de funções de fluência dos valores medidos experimentalmente, ou seja, dos alongamentos medidos para a fibra superior e inferior na seção $S_{2}$ do modelo de viga em estudo. Também são apresentadas as curvas do modelo CEB e as curvas ajustadas para o CEB-Santos, por retroanálise e Algoritmo Genético. E por fim, as curvas ajustadas por retroanálise para o modelo de Boltzmann.

\subsubsection{Aplicação da protensão}

A Figura 6.4 exibe as curvas de função de fluência para o instante de aplicação da protensão para o alongamento na fibra superior, para os modelos CEB, CEB-Santos com curva ajustada por retroanálise e Algoritmo Genético, e Boltzmann com curva ajustada por retroanálise.

Observa-se na Figura 6.4 que as curvas do CEB-Santos ajustadas por retroanálise e por AG são idênticas e se ajustam de forma satisfatória à curva dos valores medidos. Nota-se que há um ajuste melhor da curva retroanalisada para o modelo de Boltzmann, pois ela também se ajusta bem a parcela referente ao módulo de elasticidade no momento de aplicação da carga. Verifica-se uma boa aproximação da curva do CEB à curva dos valores medidos, exceto pela parcela da deformação imediata. 
Protensão - Fibra Superior

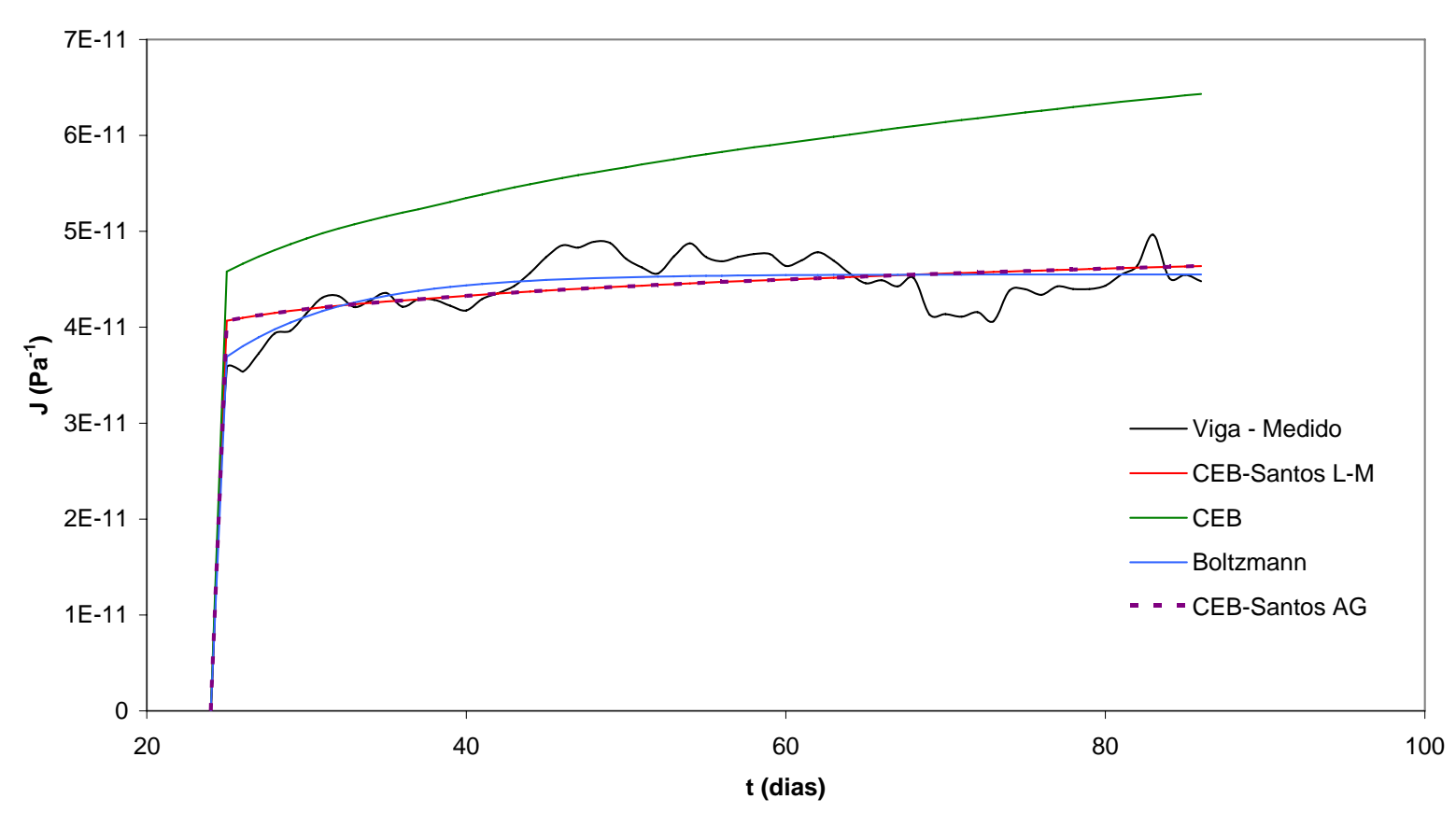

Figura 6.4. Curvas de funções de fluência para o instante de aplicação da protensão na fibra superior

A Figura 6.5 (a) apresenta os valores da função objetivo no processo de convergência ocorrido em seis iterações na retroanálise. A Figura 6.5 (b) mostra o gráfico de convergência para a solução por AG em 30 gerações. Ambas para a função de fluência do CEB-Santos.
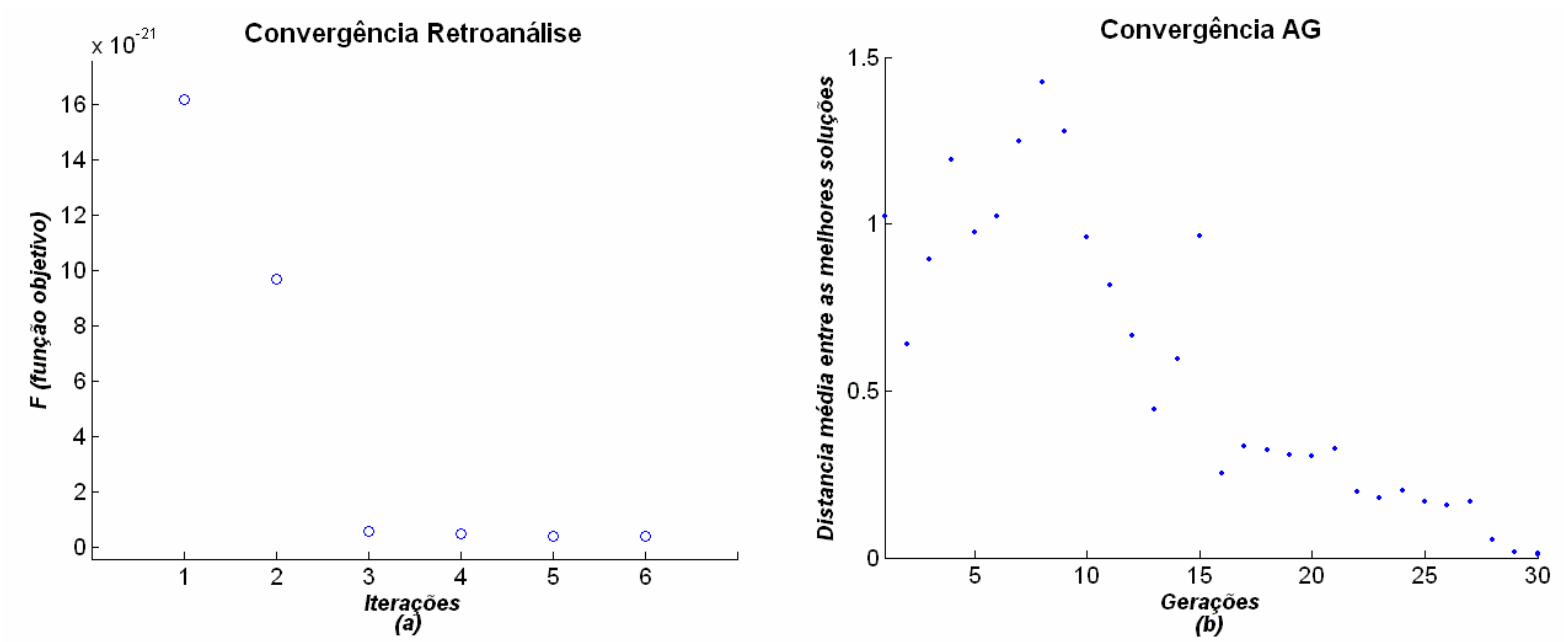

Figura 6.5. Convergência da função objetivo na retroanálise (a) e da solução em AG (b) para o instante de aplicação da protensão na fibra superior 
Apresentam-se na Figura 6.6 as diversas curvas de funções de fluência no instante de aplicação da protensão para a fibra inferior.

Observa-se que as curvas do CEB-Santos retroanalisada e por AG, e a curva ajustada para o modelo de Boltzmann possuem uma ótima aderência à curva dos valores medidos na fibra da viga monitorada. A curva do CEB tem uma boa aderência à curva dos valores medidos.

Protensão - Fibra Inferior

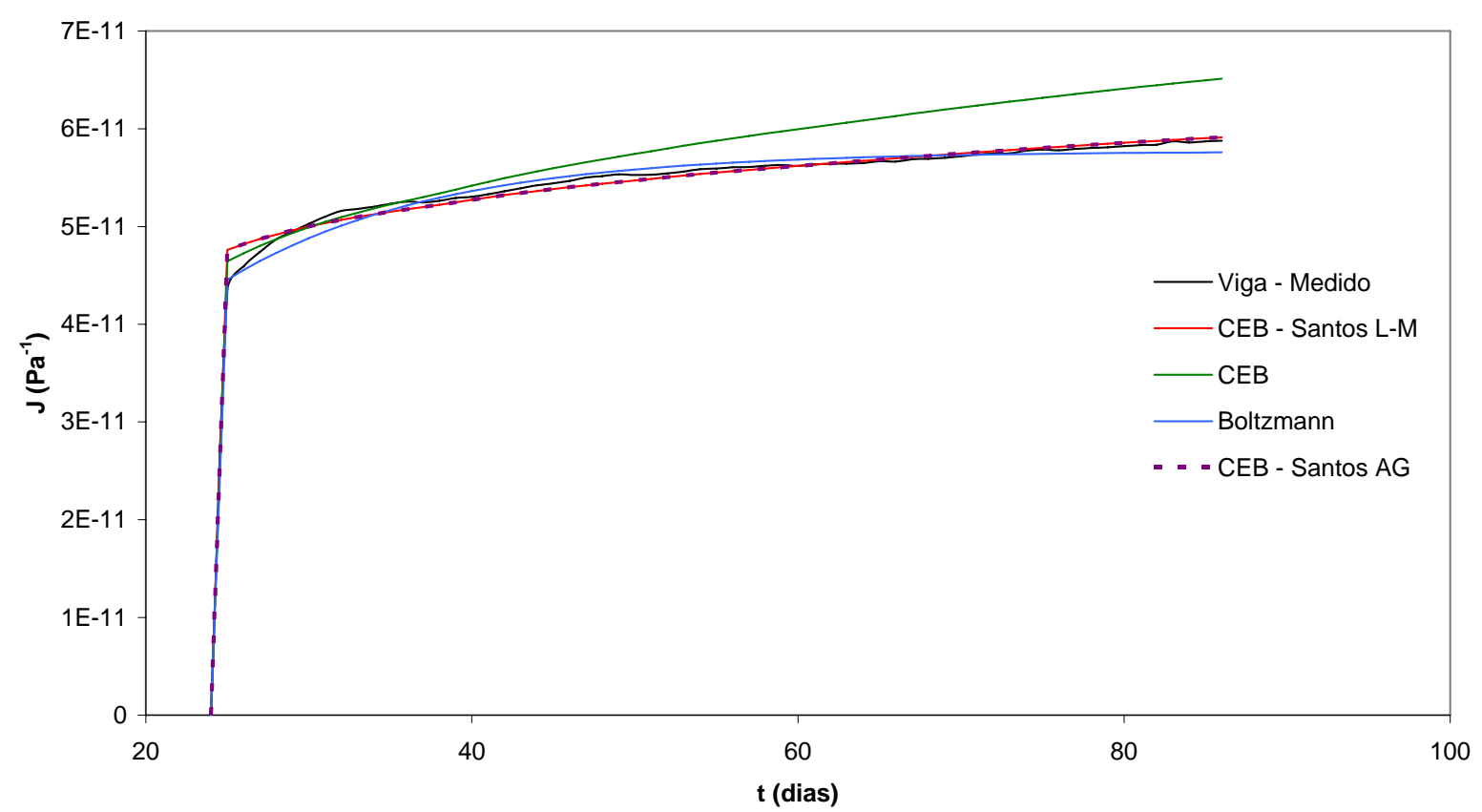

Figura 6.6. Curvas de funções de fluência para o instante de aplicação da protensão na fibra inferior

Apresenta-se nos gráfico da Figura 6.7 (a) a convergência para a função objetivo pela técnica da retroanálise e na Figura 6.7 (b) a convergência para a solução em Algoritmo Genético. 

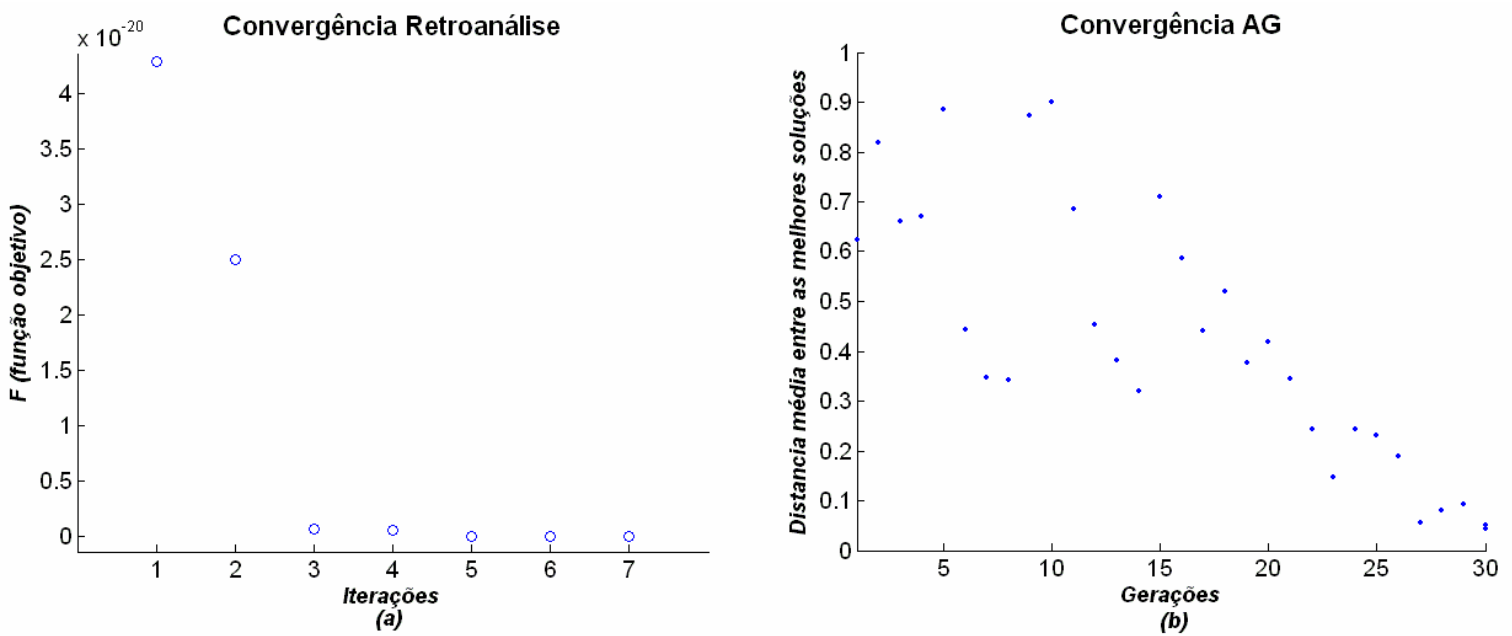

Figura 6.7. Convergência da função objetivo na retroanálise (a) e da solução em AG (b) para o instante de aplicação da protensão na fibra inferior

\subsubsection{Aplicação da ação de longa duração}

A Figura 6.8 mostra a curva de função de fluência para a deformação linear específica na fibra superior. Também são apresentadas as curvas do modelo CEB, CEB-Santos ajustada por retroanálise e por AG, e por fim, a curva ajustada para o modelo reológico de Boltzmann.

Observa-se na Figura 6.8 que a curva do CEB se aproxima mais uma vez da curva dos valores lidos. Verifica-se, também, que há um excelente ajuste para as curvas do CEB-Santos e para o modelo de Boltzmann, onde este possui um melhor ajuste na parcela referente à fluência ao tempo infinito. 
1 Aplicação - Fibra Superior

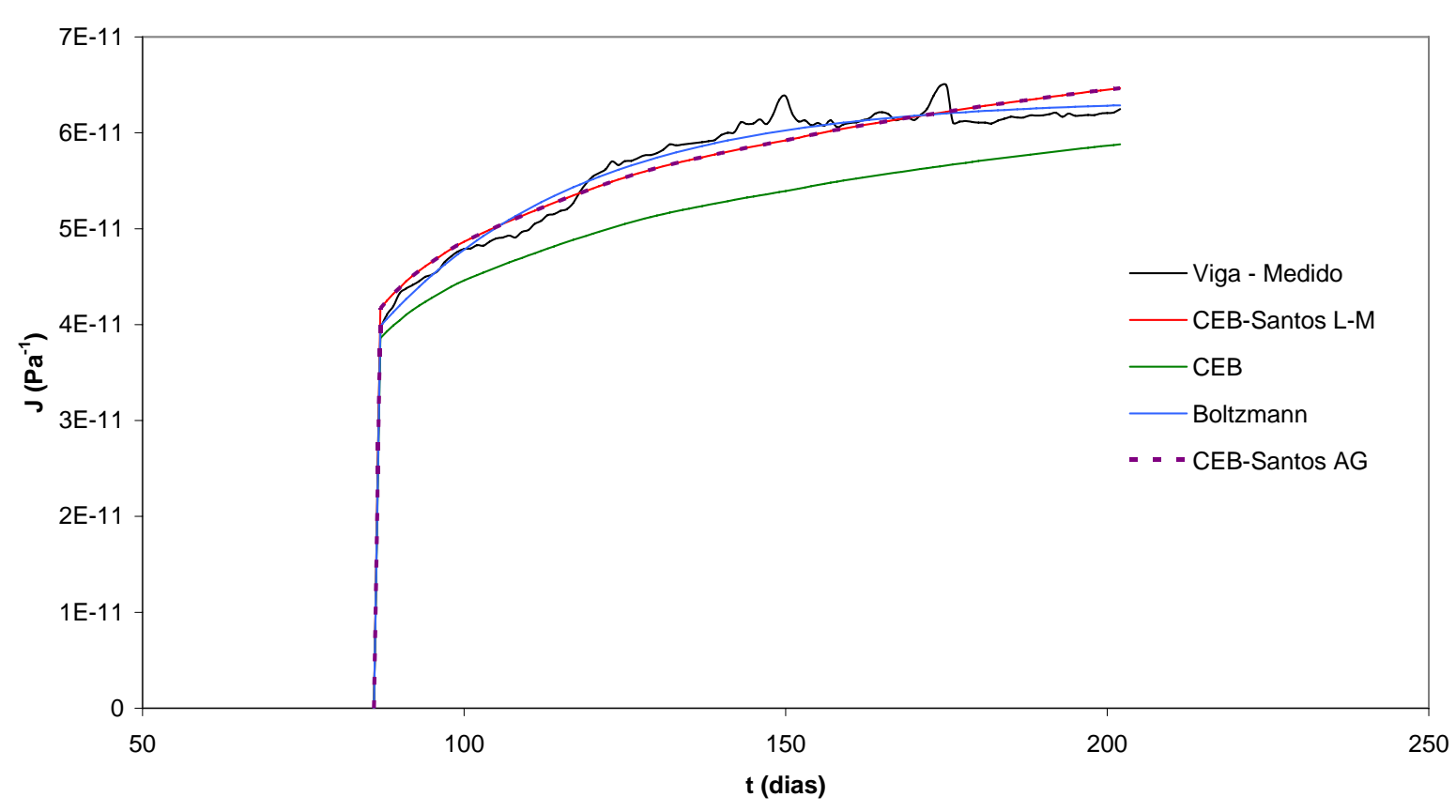

Figura 6.8. Curvas de funções de fluência para a $1^{a}$ aplicação da ação de longa duração na fibra superior

A Figura 6.9 (a) apresenta a convergência em sete iterações para a função objetivo por retroanálise. E a Figura 6.9 (b) a convergência para a solução por AG em 30 gerações. Ambas as convergências são para a função de fluência do CEB-Santos.
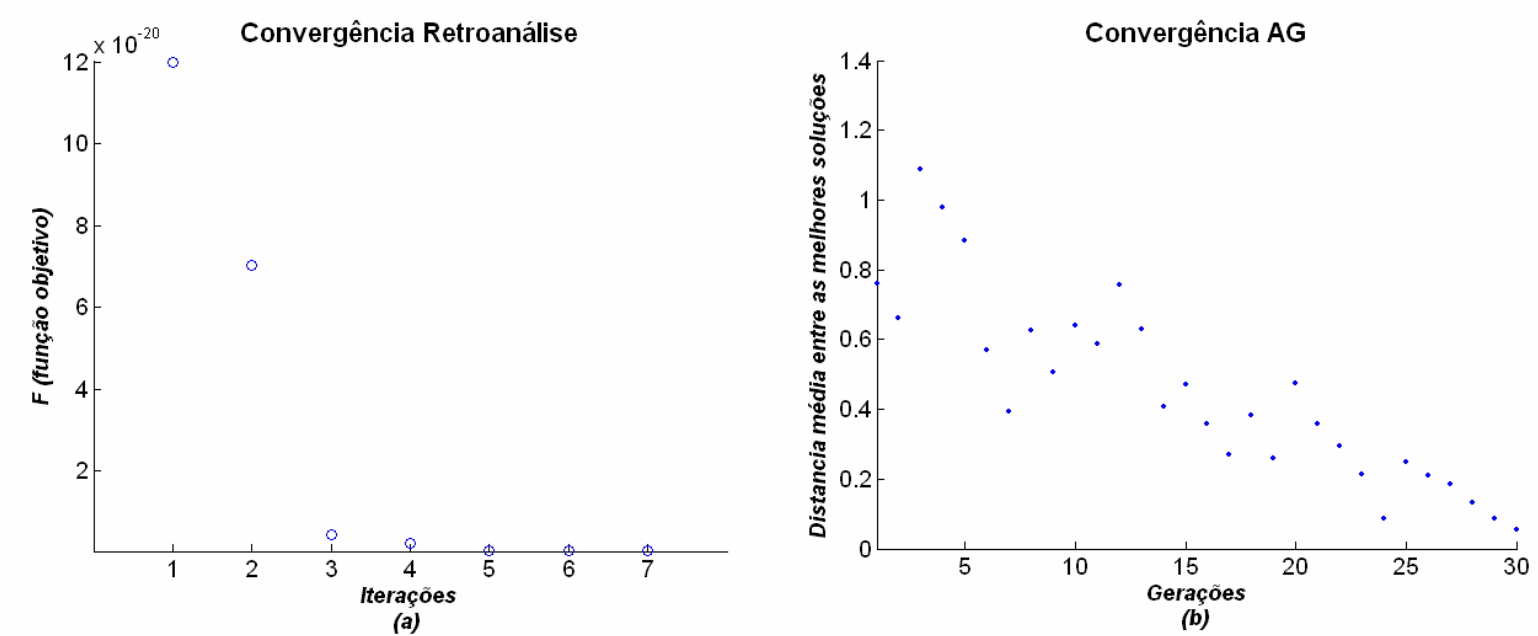

Figura 6.9. Convergência da função objetivo na retroanálise (a) e da solução em AG (b) para a $1^{\text {a }}$ aplicação da ação de longa duração na fibra superior 
Assim como na Figura 6.8, a Figura 6.10 apresenta as diversas curvas de funções de fluência para o instante de aplicação da ação de longa duração na fibra inferior.

\section{Aplicação - Fibra Inferior}

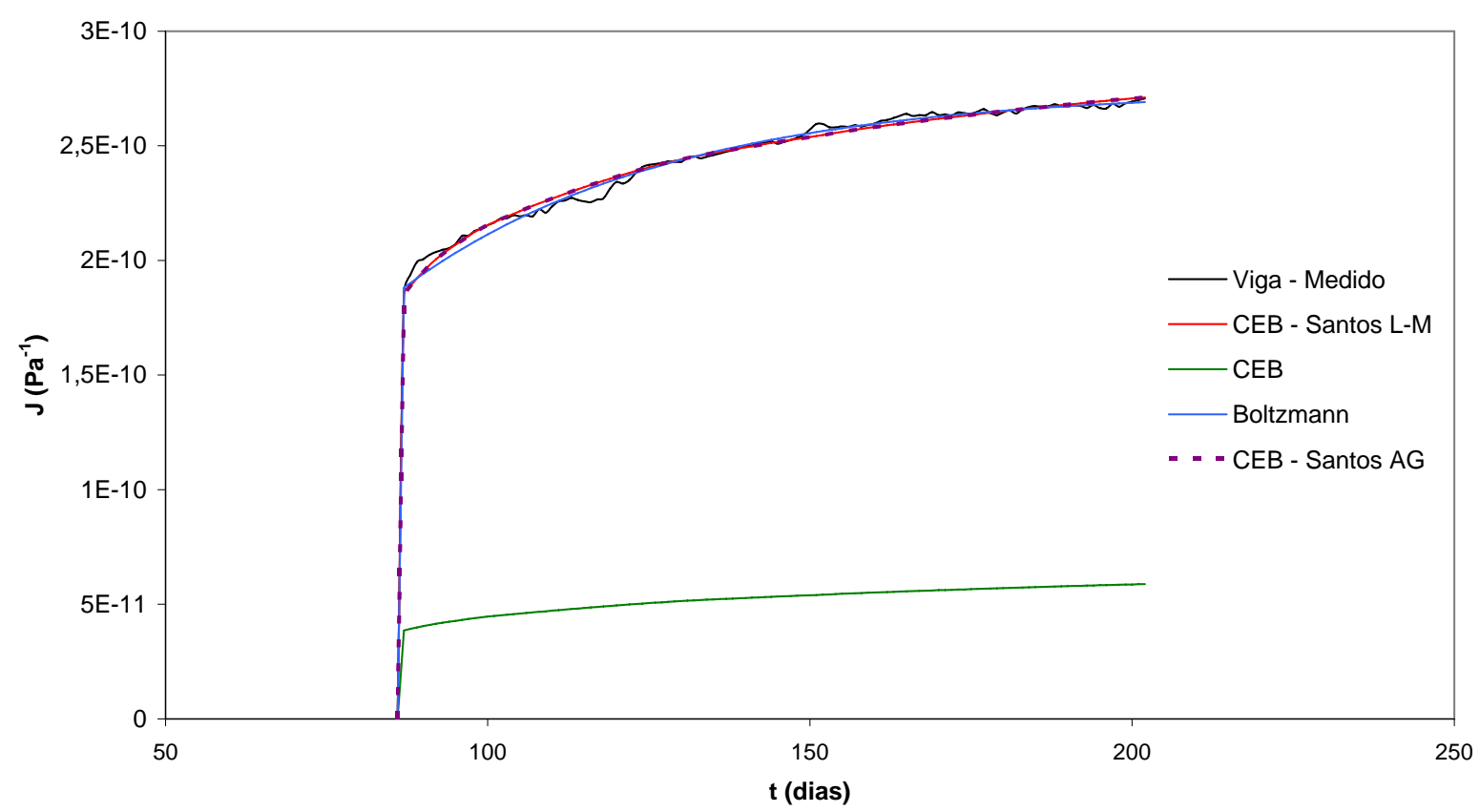

Figura 6.10. Curvas de funções de fluência para a $1^{a}$ aplicação da ação de longa duração na fibra inferior

Ressalta-se na Figura 6.10 que mais uma vez há uma excelente aderência entre a curva do alongamento medido na fibra inferior e as curvas ajustadas para o CEBSantos e o modelo de três parâmetros. Constata-se que a curva gerada pelo CEB é muito discrepante da curva dos valores reais e não está claro ainda a explicação desse afastamento.

A Figura 6.11 (a) e (b) apresentam, respectivamente, os valores da função objetivo para a convergência por retroanálise e a convergência da solução por Algoritmo Genético. 


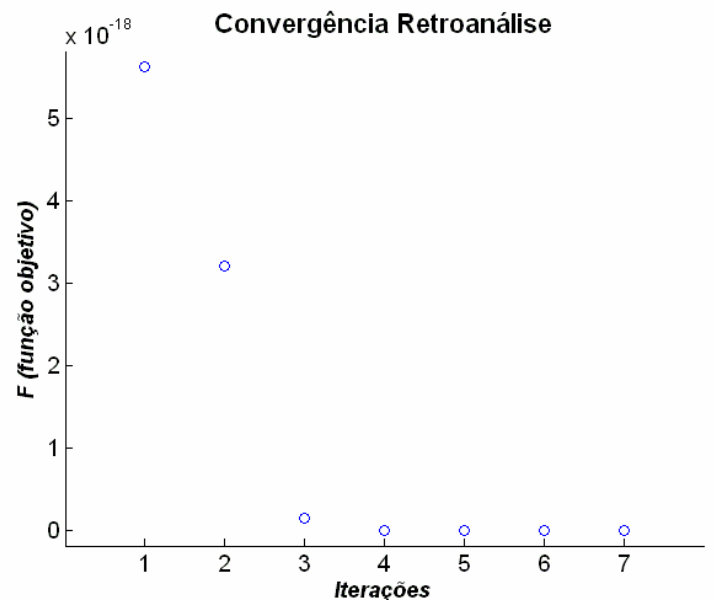

(a)

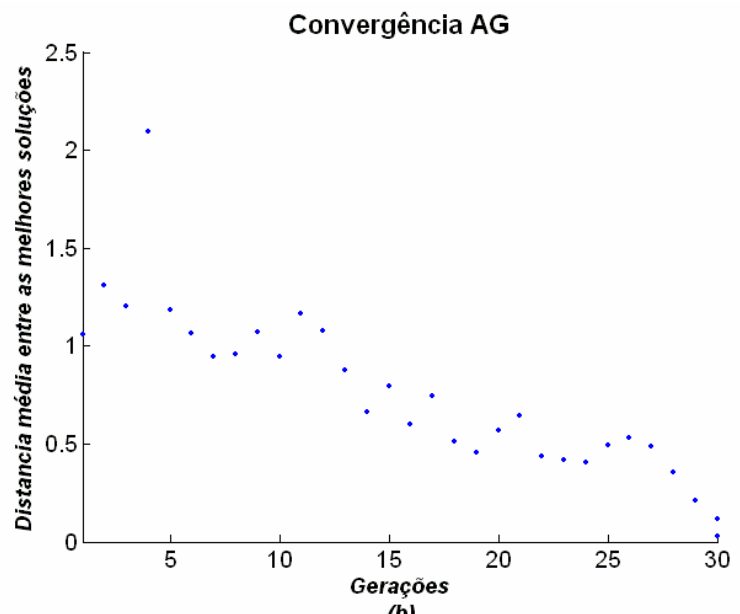

(b)

Figura 6.11. Convergência da função objetivo na retroanálise (a) e da solução em AG (b) para a $1^{a}$ aplicação da ação de longa duração na fibra inferior

\subsubsection{Descarga da ação de longa duração}

Apresentam-se na Figura 6.12 as curvas de funções de fluência para o instante de descarga da ação de longa duração para a fibra superior.

Novamente as curvas do CEB-Santos possuem uma ótima aderência à curva medida na fibra da viga monitorada. Não foi obtida a convergência da função objetivo pelo modelo de Boltzmann e por conseqüência não foi gerada a curva da função de fluência para o modelo. Verifica-se, também, que há uma discordância entre a curva gerada pelo CEB e a curva dos valores medidos, não está claro ainda uma explicação sobre este fato, mas uma das possíveis causas deste afastamento entre as curvas é a influência da armadura na viga. 


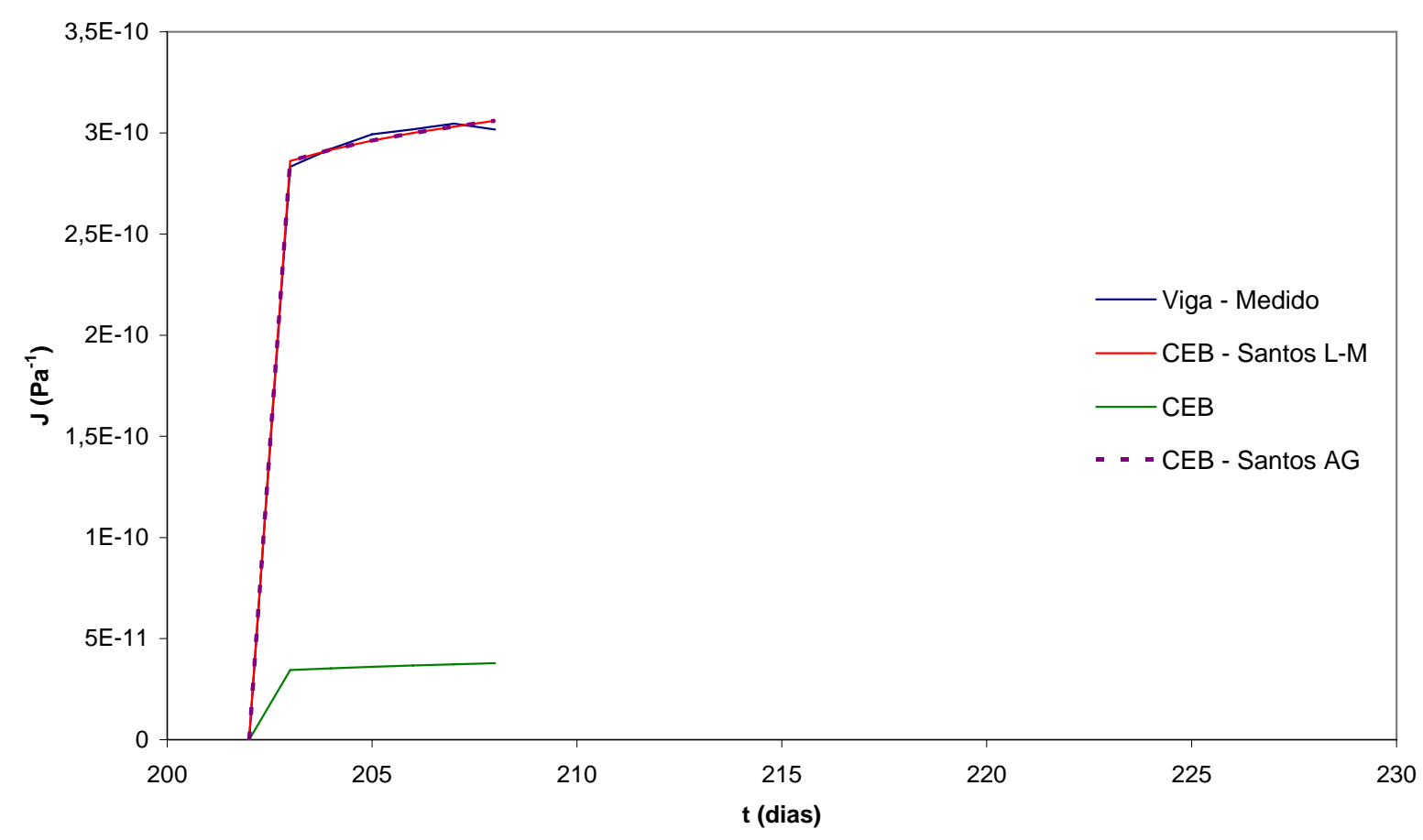

Figura 6.12. Curvas de funções de fluência para a descarga da ação de longa duração na fibra superior

A Figura 6.13 (a) apresenta o gráfico referente à convergência da função objetivo por retroanálise. A Figura 6.13 (b) a convergência para a solução por Algoritmos Genéticos.

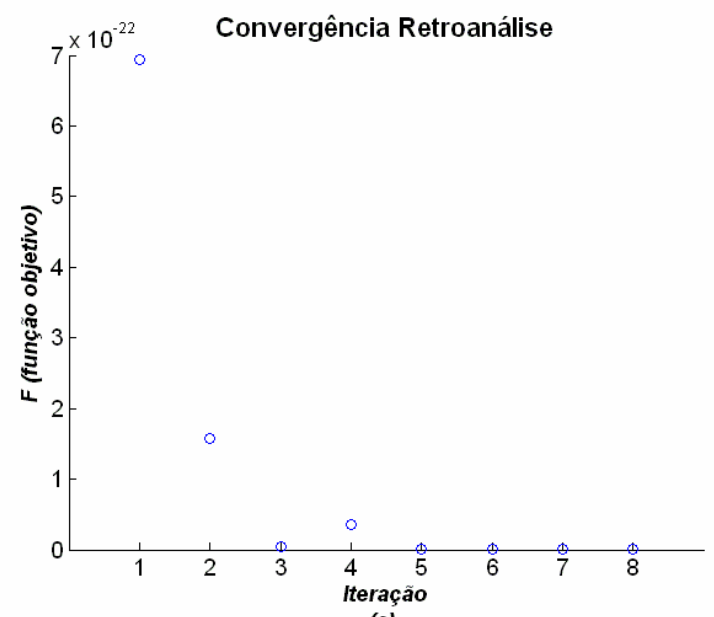

(a)

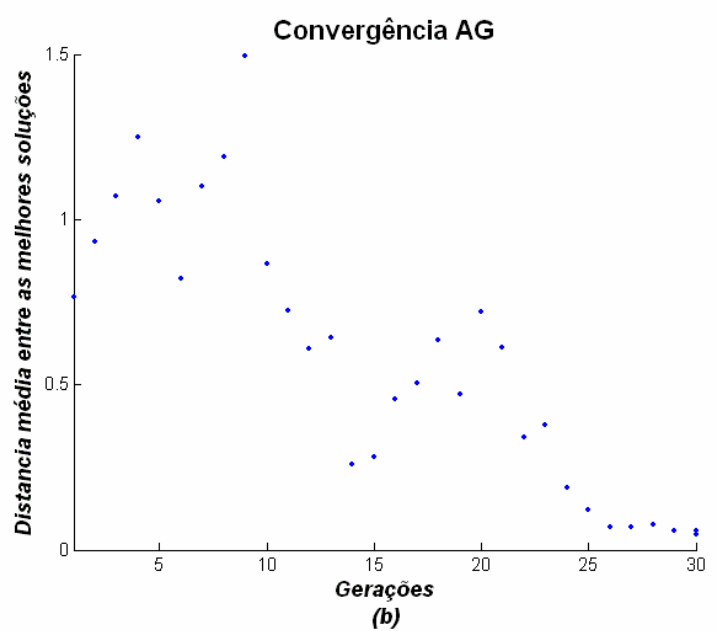

Figura 6.13. Convergência da função objetivo na retroanálise (a) e da solução em AG (b) para a descarga da ação de longa duração na fibra superior 
Observa-se no gráfico da Figura 6.14 que há uma aproximação da curva gerada pelo modelo do CEB. Também são mostradas as curvas ajustadas para o CEBSantos com o uso da técnica da retroanálise e dos Algoritmos Genéticos.

Descarga - Fibra Inferior

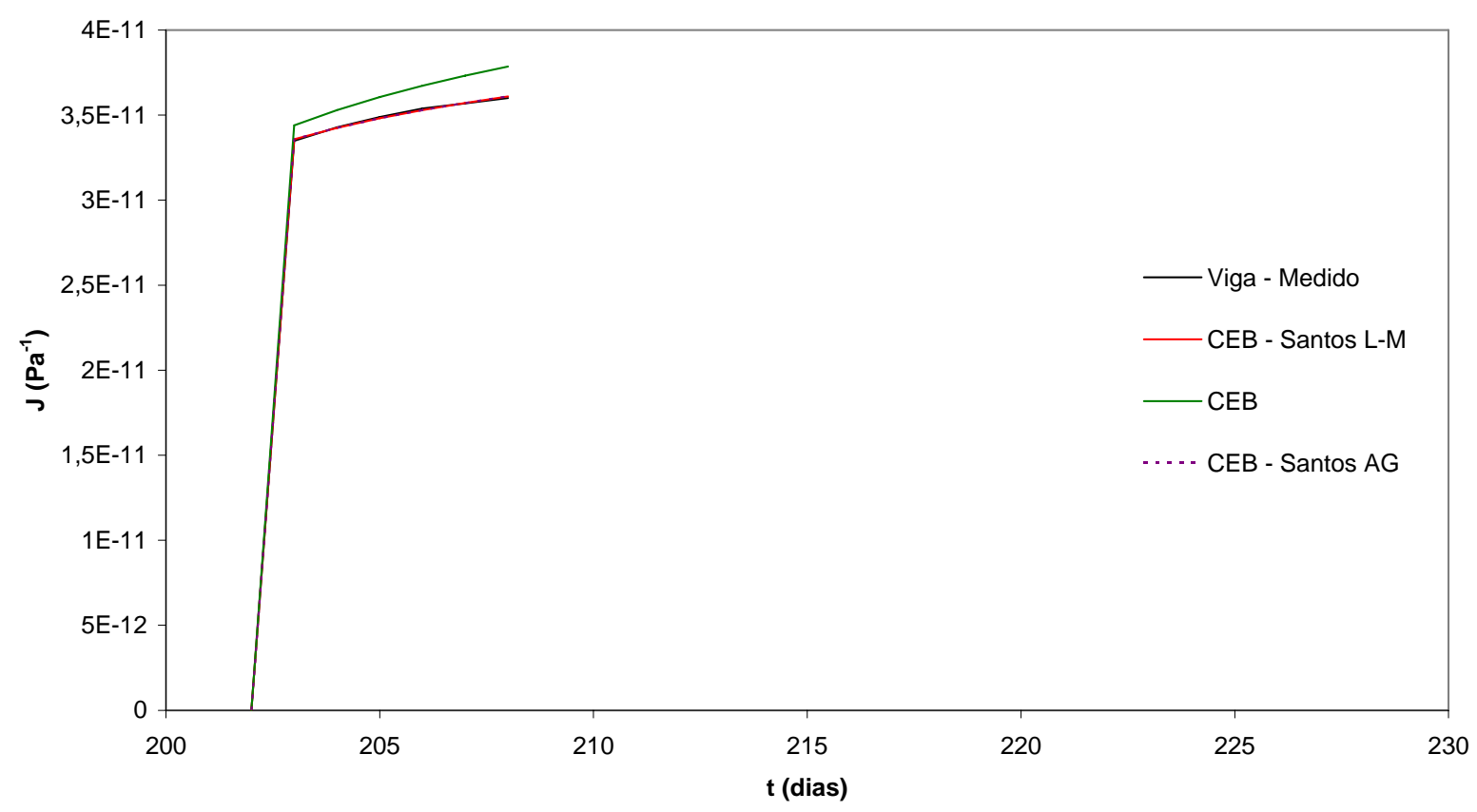

Figura 6.14. Curvas de funções de fluência para a descarga da ação de longa duração na fibra inferior

Nota-se mais uma vez que há uma excelente aderência entre a curva dos alongamentos medidos na fibra inferior e as curvas ajustadas para o CEB-Santos. A curva do CEB tem uma boa aderência à curva dos valores medidos.

A convergência na identificação dos parâmetros para a técnica da retroanálise e por Algoritmos Genéticos é apresentada na Figura 6.15 (a) e (b), respectivamente. 

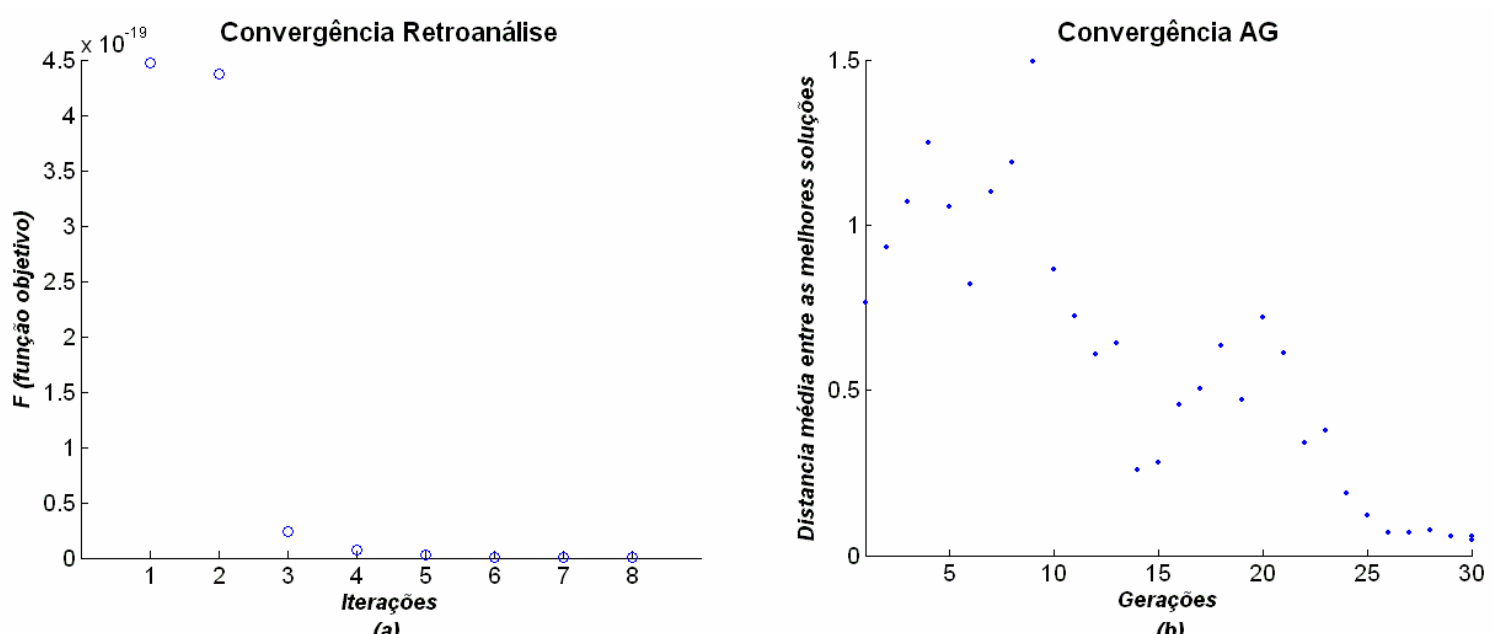

(a)

(b)

Figura 6.15. Convergência da função objetivo na retroanálise (a) e da solução em AG (b) para a descarga da ação de longa duração na fibra inferior

\subsubsection{Segunda aplicação da ação de longa duração}

A seguir são apresentados os gráficos gerados pelas curvas de funções de fluência para a segunda aplicação do carregamento de longa duração.

A Figura 6.16 mostra as curvas de funções de fluência para o alongamento sofrido na fibra superior, pelos modelos do CEB e CEB-Santos, e a curva ajustada para o modelo de Boltzmann.

Observa-se na Figura 6.16 um excelente ajuste entre a curva dos valores medidos, do modelo CEB-Santos (retroanalisado e por Algoritmo Genético) e de Boltzmann retroanalisado. A curva gerada pela função de fluência do modelo do CEB tem uma boa aproximação da curva dos valores lidos, exceto pela parcela referente à deformação imediata. 
2 Aplicação - Fibra Superior

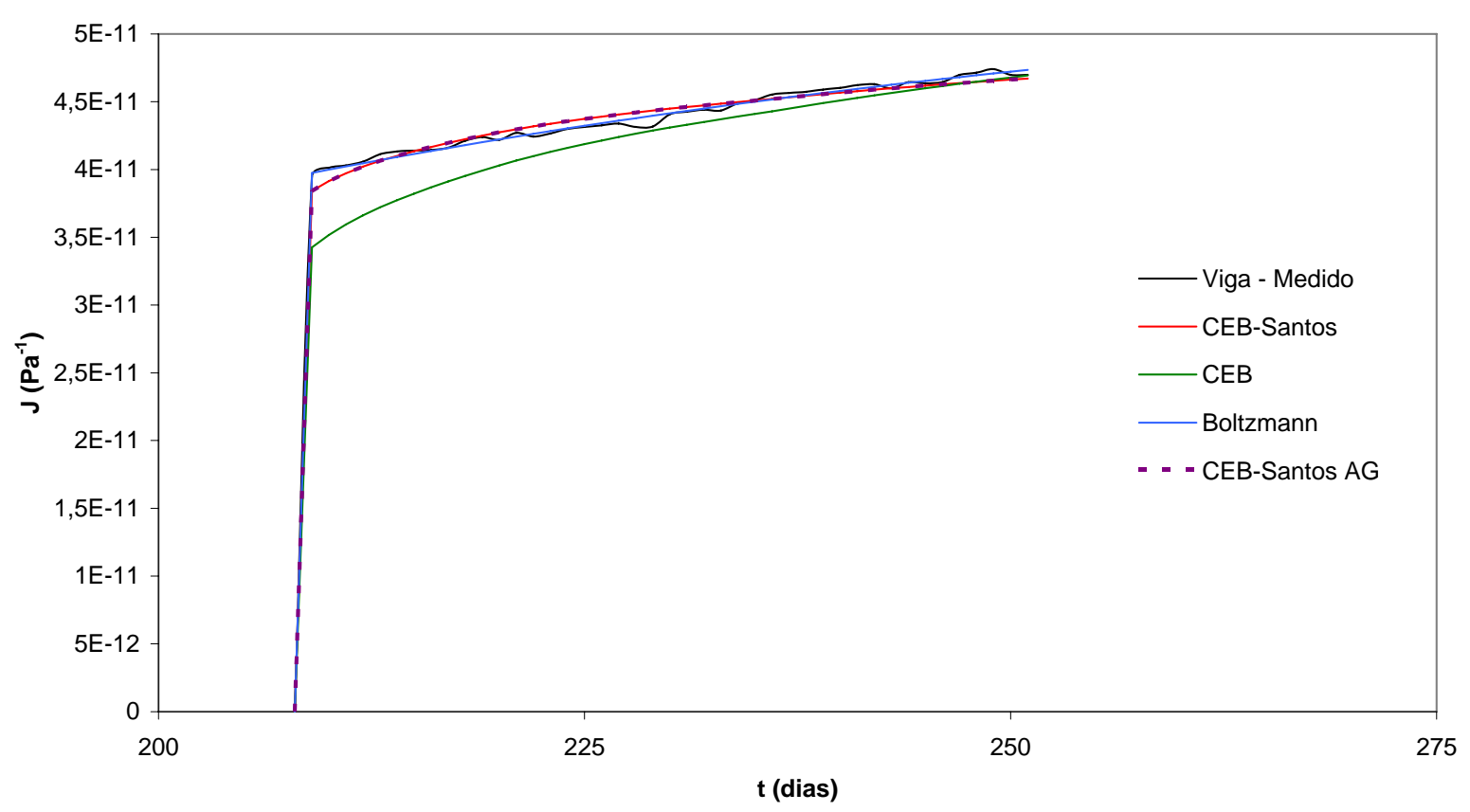

Figura 6.16. Curvas de funções de fluência para a $2^{\mathrm{a}}$ aplicação da ação de longa duração na fibra superior

A Figura 6.17 apresenta as convergências para os métodos utilizados na identificação dos parâmetros $C_{3}$ e $C_{4}$. A convergência da função objetivo em sete iterações por retroanálise e a convergência da solução por Algoritmo Genético.
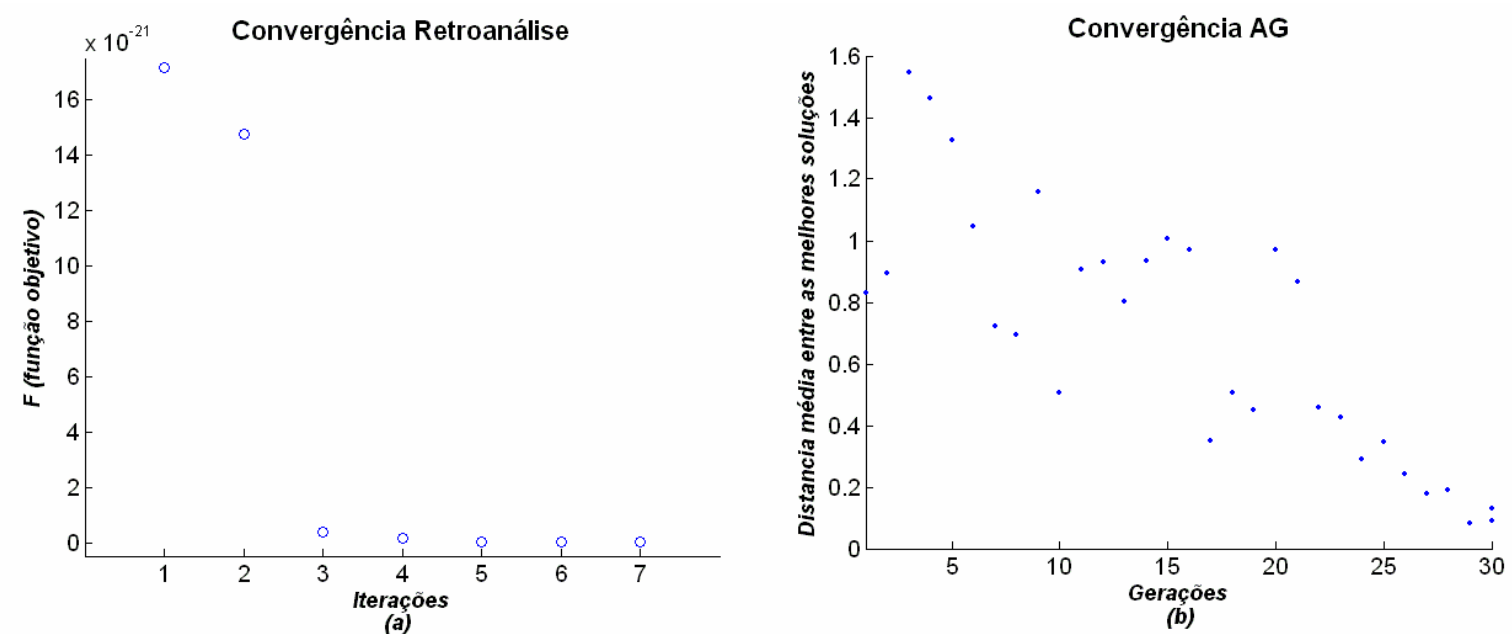

Figura 6.17. Convergência da função objetivo na retroanálise (a) e da solução em AG (b) para a $2^{a}$ aplicação da ação de longa duração na fibra superior 
A Figura 6.18 apresenta as diversas curvas de funções de fluência para a segunda aplicação da ação de longa duração na fibra inferior.

\section{Aplicação - Fibra Inferior}

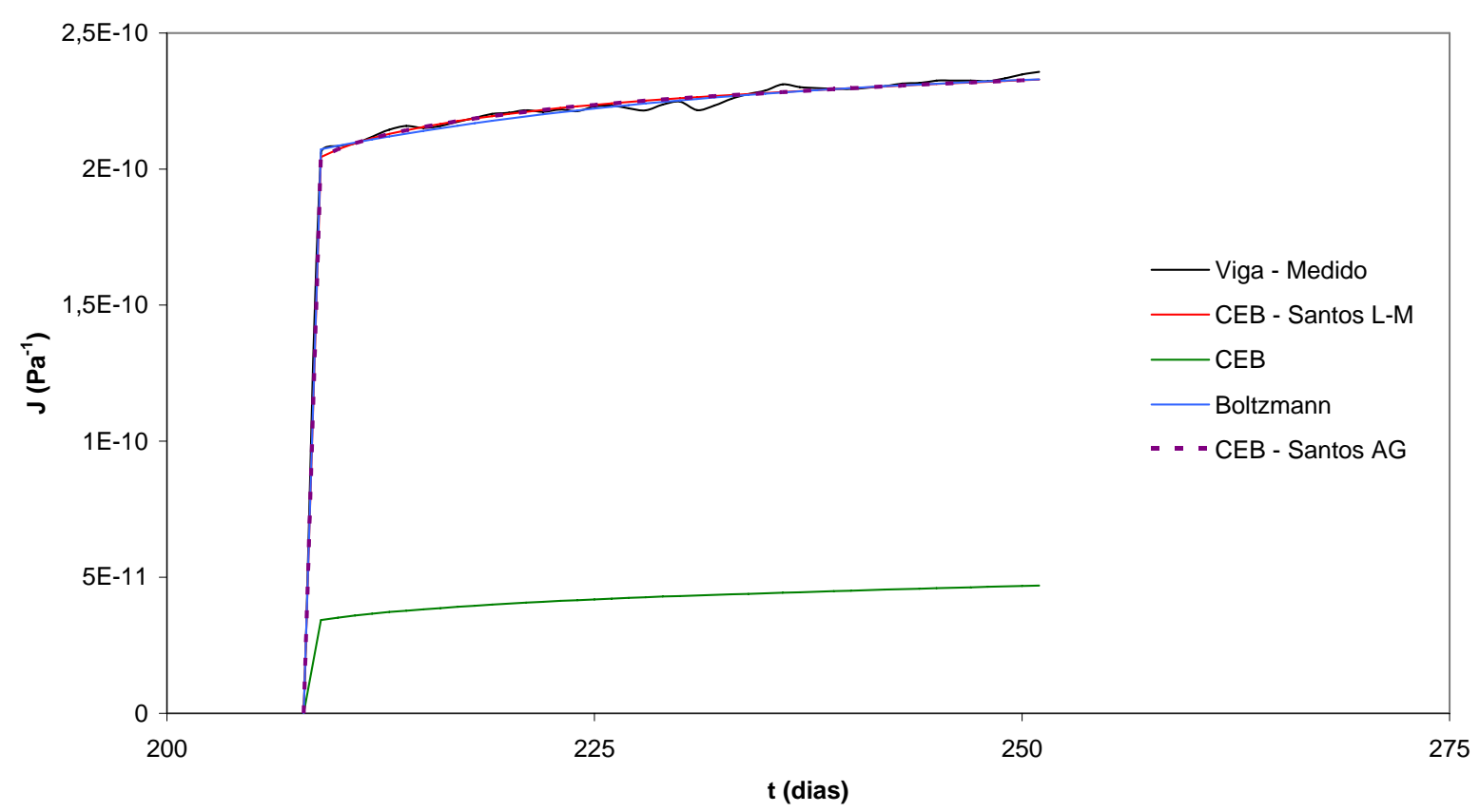

Figura 6.18. Curvas de funções de fluência para a $2^{a}$ aplicação da ação de longa duração na fibra inferior

Nota-se, mais uma vez, que há uma excelente aderência entre as curvas de funções de fluência ajustadas para o modelo CEB-Santos e Boltzmann, e a curva gerada pelas medidas efetuadas na fibra inferior. Verifica-se na Figura 6.18 que a curva gerada pela função de fluência do modelo do CEB se distancia bastante da curva determinada pelos alongamentos medidos na viga ensaiada.

Indica-se na Figura 6.19 (a) os valores da função objetivo para convergência ocorrida em oito iterações por retroanálise e na Figura 6.19 (b) a convergência da solução por Algoritmos Genéticos. 

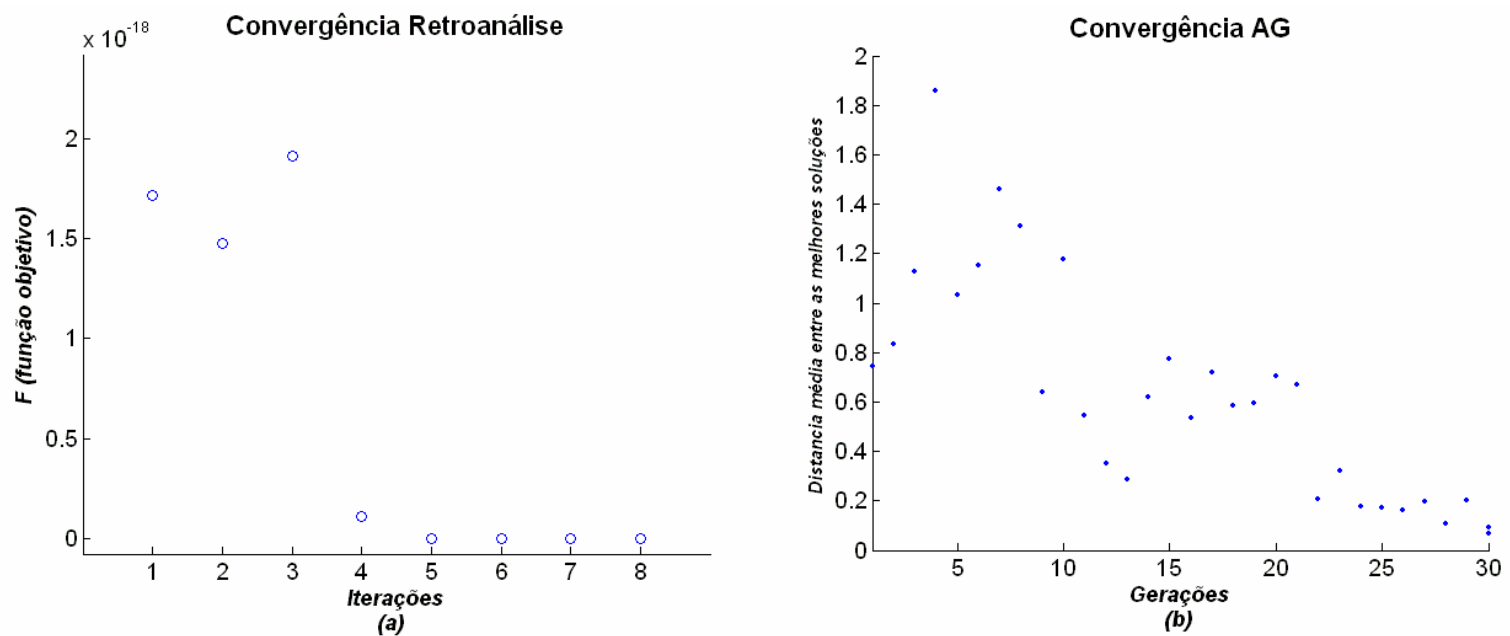

Figura 6.19. Convergência da função objetivo na retroanálise (a) e da solução em AG (b) para a $2^{a}$ aplicação da ação de longa duração na fibra inferior 


\section{OBSERVAÇÕES FINAIS}

A finalidade deste trabalho foi apresentar uma análise da deformação por fluência em uma viga monitorada no LABEST-FEUP, por estudo das funções de fluência em cada instante de carregamento em uma viga de concreto armado e protendido, simplesmente apoiada, submetida a um histórico de carregamento.

Essa análise foi fundamentada na adoção de conceitos de comportamento linear para concreto, como a superposição de efeitos.

O estudo foi baseado em comparações entre as curvas de funções de fluência que resultam dos valores medidos experimentalmente, do modelo CEB, CEB-Santos (com ajuste dos coeficientes $C_{3}$ e $C_{4}$ ) e do modelo reológico de três parâmetros de Boltzmann (com ajuste dos coeficientes $E_{0}, E_{1}$ e $\eta_{1}$ ).

Para a identificação dos parâmetros $C_{3}$ e $C_{4}$ do modelo CEB-Santos foram empregados dois métodos o de retroanálise e o dos Algoritmos Genéticos. Para os dois métodos, os parâmetros encontrados foram os mesmos e isso se deve ao bom comportamento da função objetivo, ou seja, as funções apresentaram apenas um ponto de mínimo bem definido fazendo com que os dois métodos convergissem para a mesma solução. Verifica-se que a aplicação dos coeficientes $C_{3}$ e $C_{4}$ ao modelo CEB é uma maneira eficiente de ajustar esse modelo aos valores experimentais. Contudo, esses parâmetros variam a cada instante de carregamento e com o ponto estudado.

Em relação ao modelo de Boltzmann os valores dos parâmetros que correspondem à parcela viscoelástica do modelo, $E_{1}$ e $\eta_{1}$, são distintos a cada instante de carregamento $t_{0}$, como deveria ser. Entretanto, eles também variam com o ponto estudado quando deveriam representar uma característica do concreto como um todo. 
Nota-se que na maioria dos casos o ajuste efetuado para o modelo de Boltzmann obteve uma maior aderência às curvas dos alongamentos medidos que o ajuste para o modelo CEB-Santos.

O ajuste das curvas de funções de fluência, por meio da identificação de parâmetros, é obtido com a aplicação de técnicas diversas que não representam um obstáculo difícil de ser superado. Porém, esses valores encontrados são variáveis em dois pontos na mesma seção e essa constatação representa uma questão a ser tratada e um obstáculo sério no que diz respeito ao uso desses resultados, que não seja o de simples ajuste de curvas.

Algumas sugestões para a continuidade deste trabalho são expostas a seguir:

- Estudo aprofundado da influência da armadura na análise da fluência e da retração de peças de concreto;

- Emprego de prismas de fluência carregados em diversas idades conforme plano de carga na estrutura;

- Monitoramento em estruturas simples em laboratórios para a análise de questões postas neste trabalho;

- Monitoramento em estruturas reais para comparar resultados previstos com os medidos. Setores.

Com esses estudos uma série de questões constatadas neste trabalho poderão melhor ser compreendidas e, portanto, explicadas. 


\section{REFERÊNCIAS}

\section{BIBLIOGRAFIAS REFERENCIADAS}

CASTRO, R. E. Otimização de estruturas com multi-objetivos via Algoritmos Genéticos. Tese de Doutorado - Programa de Engenharia Civil, COPPE/UFRJ, Rio de Janeiro, RJ, Brasil, 2001.

COMITE EURO-INTERNATIONAL DU BETON. Model Code 1990: Design Code. Thomas Telford, 1990.

COSTA, A. Aplicação das técnicas de retroanálise em obras civis. Dissertação de Mestrado - Escola Politécnica, Universidade de São Paulo, São Paulo, Brasil, 2000.

Identificação de parâmetros em obras civis. Tese de Doutorado Escola Politécnica, Universidade de São Paulo, São Paulo, Brasil, 2006.

HORVATH Jr., R. Decomposição das parcelas de Deformações Lineares em um Viga de Concreto Armado e Protendido em Condições de Utilização: Retroanálise na Identificação de Parâmetros. Dissertação de Mestrado - Escola Politécnica, Universidade de São Paulo, São Paulo, Brasil, 2005.

MEHTA, P.K. MONTEIRO, P.J.M. Concreto: estrutura, propriedades e materiais. São Paulo, PINI, 1994.

NEVILLE, A. M. Propriedades do concreto. São Paulo, PINI, 1997

SOUSA, H.; FÉLIX, C.; FIGUEIRAS, J.A. Comportamento Experimental de uma Viga de Betão Armado e Pré-Esforçado, 2002. 
SOUZA LIMA, V.M.; ZAGOTTIS, D.L.; ANDRÉ, J.C. As Tensões de Origem Térmica nas Barragens e o Comportamento Viscoelástico do Concreto. $X I$ Seminário Nacional de Grandes Barragens. Fortaleza, Brasil. 1976.

SILVA, E.E. Otimização de estruturas de concreto armado utilizando algoritmo genético. Dissertação (mestrado) - Escola Politécnica da Universidade de São Paulo. Departamento de Engenharia de Estruturas e Fundações, São Paulo, Brasil, 2001.

VAS, P. Artificial inteligence based eletrical machines and drives: aplications of fuzzy neural and genetic algorithm based techniques. Oxford, New York - Oxford University Press, 1999. 


\section{BIBLIOGRAFIAS CONSULTADAS}

BAZAÄNT, Z.P. Mathematical Modeling of Creep and Shrinkage of Concrete. Northwestern University, Envanston, Illinois, EUA, 1988.

CARBONO, A. J. J.; MENEZES, I. F. M.; MARTHA, L. F. Mooring Pattern Optimization using Genetic Algorithms. 6th World Congresses of Structural and Multidisciplinary Optimization. Rio de Janeiro, Brasil, 2005.

COSTA, A.; ANDRÉ, J.C. Estudo dos métodos de Newton-Raphson e de GaussNewton na identificação de parâmetros em problemas de retroanálise. In: Congresso temático de dinâmica e controle da SBMAC, Ilha Solteira, 2004. Anais. São Paulo, 2004.

HOLLAND, J. H. Adaptation in Natural and Artificial Systems. The University of Michigan Press, Ann Arbor, MI, 1975.

LIMA, C.R.N.; HORVARTH Jr, R; ANDRÉ, J.C. Análise da deformação por fluência em uma viga de concreto armado e protendido II: Retroanálise e algoritmos genéticos. VI Simpósio EPUSP sobre estruturas de concreto, São Paulo, Brasil, 2006.

PIMENTA, P.M.; SANTOS, H.C. Análise e retro-análise de estruturas de concreto sujeitas à deformação lenta. IV Simpósio EPUSP sobre estruturas de concreto, São Paulo, Brasil, 2000.

SANTOS, H.C.; PIMENTA, P.M. Um modelo consistente para representação da deformação lenta do concreto. V Congresso de Engenharia Civil, Juiz de Fora MG, Belo Horizonte, 2002. 


\section{APÊNDICE A}

Apresentam-se nesta seção os algoritmos utilizados na implementação, no software MATLAB, do modelo CEB-Santos e, por conseguinte a técnica da retroanálise.

\%\%Retroanálise na identificação dos parâmetros C3 e C4 para o modelo CEBSantos\%\% $\%$

Num = 43; \%Número de dias sob ação de carregamento

Dia $=25 ; \%$ Dia do carregamento

$\mathrm{Fib}=1 ; \quad \%$ Fibra superior $=1$ e inferior $=2$

Carr $=2 ; \%$ Tipo de carregamento (ex: Protensão $=2$ )

$\% \% \%$ Vetor temperatura\%\%\% $\%$

$\mathrm{Tm}=[9.9 ; 9.9 ; 9.9 ; 9.9 ; 9.9 ; 9.9 ; 9.9 ; 9.9 ; 9.9 ; 9.9 ; 9.9 ; 9.9 ; 9.9 ; 9.9 ; 9.9 ; 9.9 ; 9.9 ; 9.9$; 9.9; 9.9 ;

9.9; 9.9; 9.9; 9.9; 9.9; 9.9; 9.9; 9.7; 10.0; 9.5; 9.6; 8.6; 8.3; 7.9; 7.9; 7.6; 7.3; 8.6; 10.2; 11.3;

$11.8 ; 12.2 ; 10.9 ; 11.2 ; 11.2 ; 10.9 ; 10.5 ; 9.9 ; 10.2 ; 10.2 ; 11.4 ; 11.9 ; 11.8 ; 12.2 ; 11.1 ;$ $10.6 ; 10.9 ; 11.3 ; 10.7 ; 11.1$;

10.6; 12.2; 11.8; 12.7; 13.3; 13.7; 13.7; 13.6; 13.3; 13.1; 13.2; 13.3; 14.0; 13.2; 14.4; $13.7 ; 14.2 ; 14.2 ; 14.1 ; 14.0$;

14.3; 13.9; 14.0; 13.0; 13.3; 12.8; 12.4; 12.1; 12.6; 11.6; 15.3; 13.1; 13.0; 12.8; 13.0; $13.7 ; 14.9 ; 16.3 ; 14.2 ; 12.7$;

$12.2 ; 12.3 ; 12.3 ; 12.5 ; 13.7 ; 14.6 ; 14.6 ; 14.2 ; 13.9 ; 16.3 ; 14.5 ; 16.1 ; 16.8 ; 16.8 ; 17.1 ;$ $17.6 ; 17.5 ; 17.1 ; 17.2 ; 18.1$;

19.1; 18.9; 18.8; 18.6; 18.7; 18.6; 18.2; 17.9; 17.8; 17.4; 17.2; 15.9; 15.2; 15.7; 15.1; $15.2 ; 15.3 ; 15.4 ; 15.5 ; 15.6$;

$15.7 ; 15.8 ; 15.9 ; 15.1 ; 15.2 ; 15.3 ; 15.4 ; 15.5 ; 15.6 ; 15.7 ; 16.8 ; 18.1 ; 19.4 ; 20.0 ; 19.9$; $19.6 ; 19.1 ; 18.5 ; 17.8 ; 17.7$;

$17.6 ; 17.3 ; 16.5 ; 16.7 ; 17.5 ; 18.0 ; 17.5 ; 18.2 ; 18.0 ; 17.6 ; 17.4 ; 17.7 ; 17.7 ; 18.0 ; 18.3$; $19.3 ; 19.3 ; 18.4 ; 18.6 ; 19.5$; 
18.7; 17.8; 17.5; 18.2; 17.2; 18.1; 18.1; 18.0; 17.9; 18.6; 19.6; 19.8; 19.6; 19.8; 19.4; $17.9 ; 18.6 ; 18.3 ; 17.4 ; 17.8$;

$17.2 ; 18.3 ; 19.4 ; 20.8 ; 21.4 ; 21.3 ; 21.4 ; 22.0 ; 22.0 ; 21.6 ; 21.6 ; 21.6 ; 22.0 ; 21.5 ; 21.4$; $22.7 ; 23.5 ; 23.3 ; 23.7 ; 24.2$;

$24.1 ; 23.9 ; 23.8 ; 23.0 ; 23.0 ; 22.9 ; 23.1 ; 23.3 ; 22.9 ; 22.1 ; 21.6 ; 21.7 ; 21.9 ; 22.2 ; 22.7$; $23.5 ; 24.7 ; 25.5 ; 25.8 ; 25.8$;

$25.8 ; 25.8 ; 25.8 ; 25.8 ; 25.8 ; 25.8 ; 25.8 ; 25.8 ; 25.8 ; 25.8 ; 25.8 ; 25.8 ; 25.8 ; 25.8]$;

Vm = xlsread('Funcao_Fluencia','Protensao'); \%Valores medidos

$\% \% \% \%$ T(tempo corrigido) $\% \% \% \% \%$

for $\mathrm{i}=2: 253$

$T(1)=0 ;$

$\mathrm{T}(\mathrm{i})=\exp (13.65-(4000 /(273+\mathrm{Tm}(\mathrm{i}))))+\mathrm{T}(\mathrm{i}-1)$;

end

for $\mathrm{i}=2: 253$

$\operatorname{Bcc}(1)=0$;

$B c c(i)=\exp \left(s^{\star}(1-(28 / T(i)) \wedge 0.5)\right)$;

end

for $\mathrm{i}=1: 253$

$\operatorname{BetaE}(\mathrm{i})=(\operatorname{Bcc}(\mathrm{i}))^{\wedge} 0.5 ; \% \operatorname{BetaE}$

end

$\mathrm{Ec} 28=(\mathrm{Ec0})^{\star}((\mathrm{fcm} / \mathrm{fcm} 0))^{\wedge}(1 / 3) ; \% \mathrm{Ec} 28$

$\% \% \% \%$ Ecit(módulo de elasticidade com correção da temperatura)\%\%\%\%\% EciT = BetaE*Ec28;

$\% \% \% \% \%$ idade do concreto (efeito do tipo e da cura do cimento)\%\%\%\%\% for $i=1: 253$

$\mathrm{V}=\mathrm{T}(\mathrm{i})^{\star}\left(1+\left(9 /\left(2+\left((\mathrm{T}(\mathrm{i}))^{\wedge} 1.2\right)\right)\right)\right)^{\wedge} \mathrm{a} ;$

if $\mathrm{V}<0.5$ 


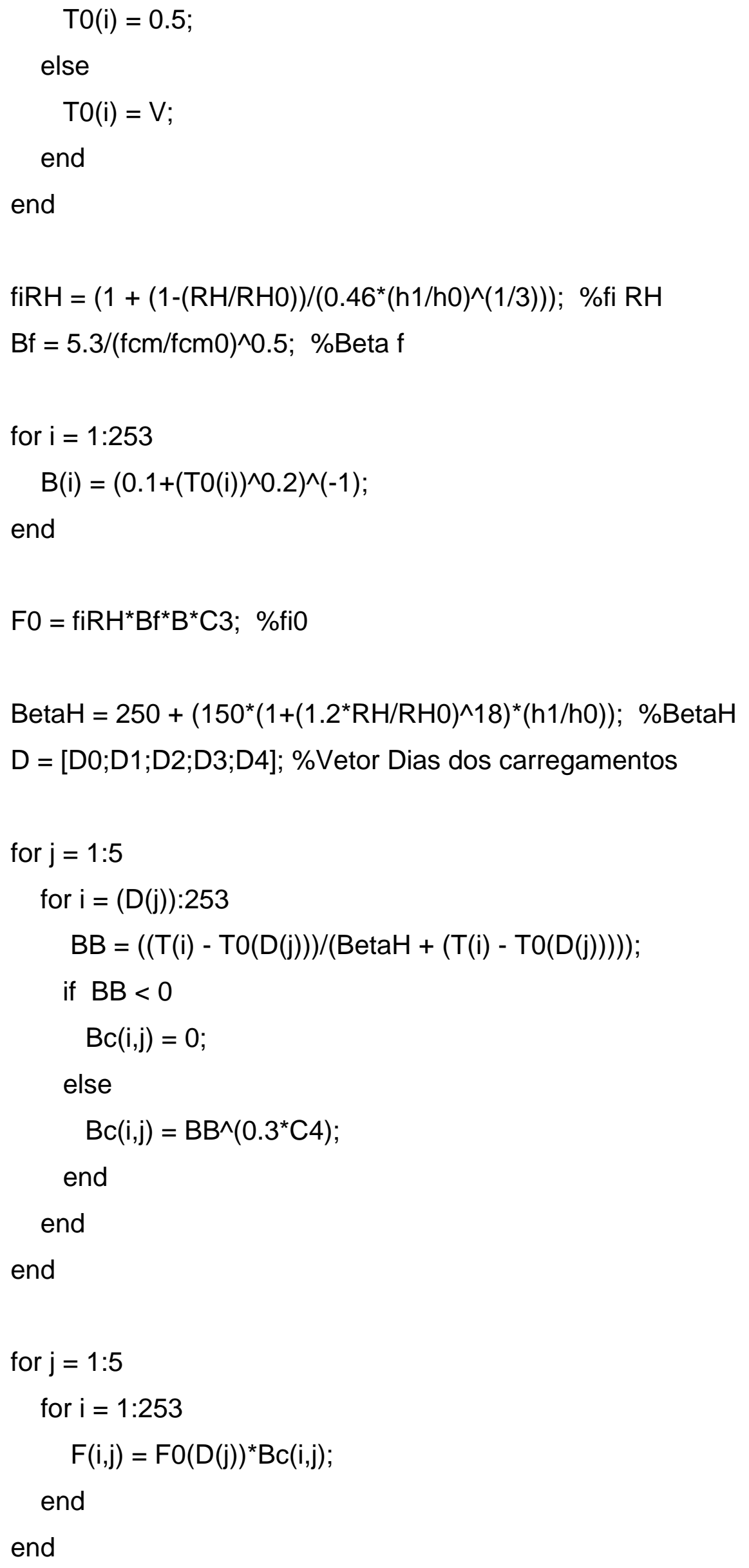


$Z=[1 ; 2 ; 3 ; 4 ; 5]$

for $\mathrm{j}=1: 5$

for $i=1: 253$

\%Parcela de fluência devido ao momento

$J M(i, j)=(1 / E c 28)^{\star} F(i, Z(j))$;

\%Parcela de fluência devida à força normal

$J N(i, j)=(1 / E c 28)^{\star} F(i, Z(j))$;

end

end

$\% \% \% \%$ Modulo de elasticidade dado pelo CEB em cada instante de carregamento $\mathrm{Ec}=[$ Eci0;Eci1;Eci2;Eci3;Eci4];

for $\mathrm{j}=1: 5$

for $\mathrm{i}=(D(Z(j))): 253$

$\mathrm{JMO}(\mathrm{i}, \mathrm{j})=1 / \mathrm{Ec}(\mathrm{Z}(\mathrm{j})) ; \%$ Parcela imediata devido ao momento

JNO(i,j) $=1 / E c(Z(j)) ; \%$ Parcela imediata devida a força normal

end

end

\%\%\%Cálculo da Influência da armadura na deformação da viga\%\%\%

for $\mathrm{i}=2: 253$

$$
\begin{aligned}
& n(1)=0 ; \\
& n(i)=E s /(\operatorname{EciT}(i)) ;
\end{aligned}
$$

end

for $\mathrm{j}=1: 5$

for $\mathrm{i}=1: 253$

$\mathrm{S}(\mathrm{i}, \mathrm{j})=\left(\mathrm{JM}(\mathrm{i}, \mathrm{j}) /\left(2^{*} \mathrm{n}(\mathrm{i})^{*} \mathrm{ulinha}-4^{*} \mathrm{n}(\mathrm{i})^{*} \mathrm{ulinh} a^{*}(\mathrm{dlinh} a / \mathrm{hv})+1\right)\right)+(\mathrm{JN}(\mathrm{i}, \mathrm{j}) /(1+$ n(i)*ulinha));

end

end 


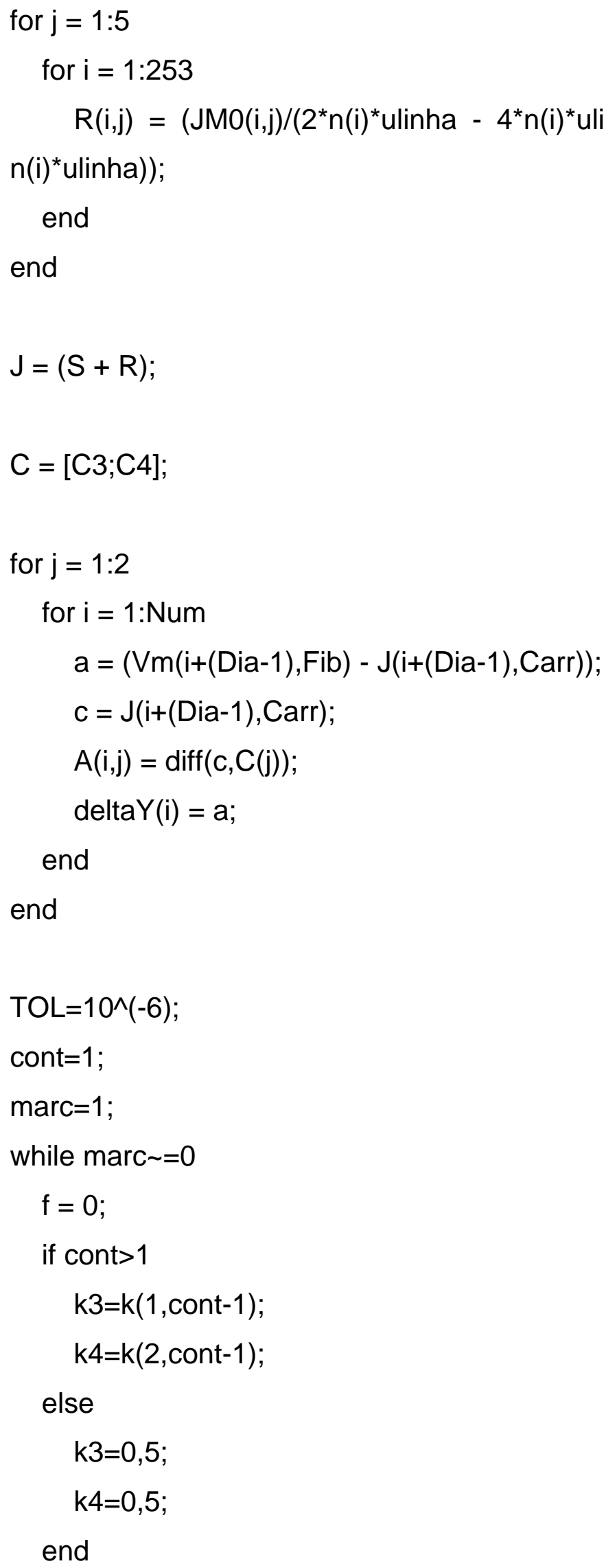




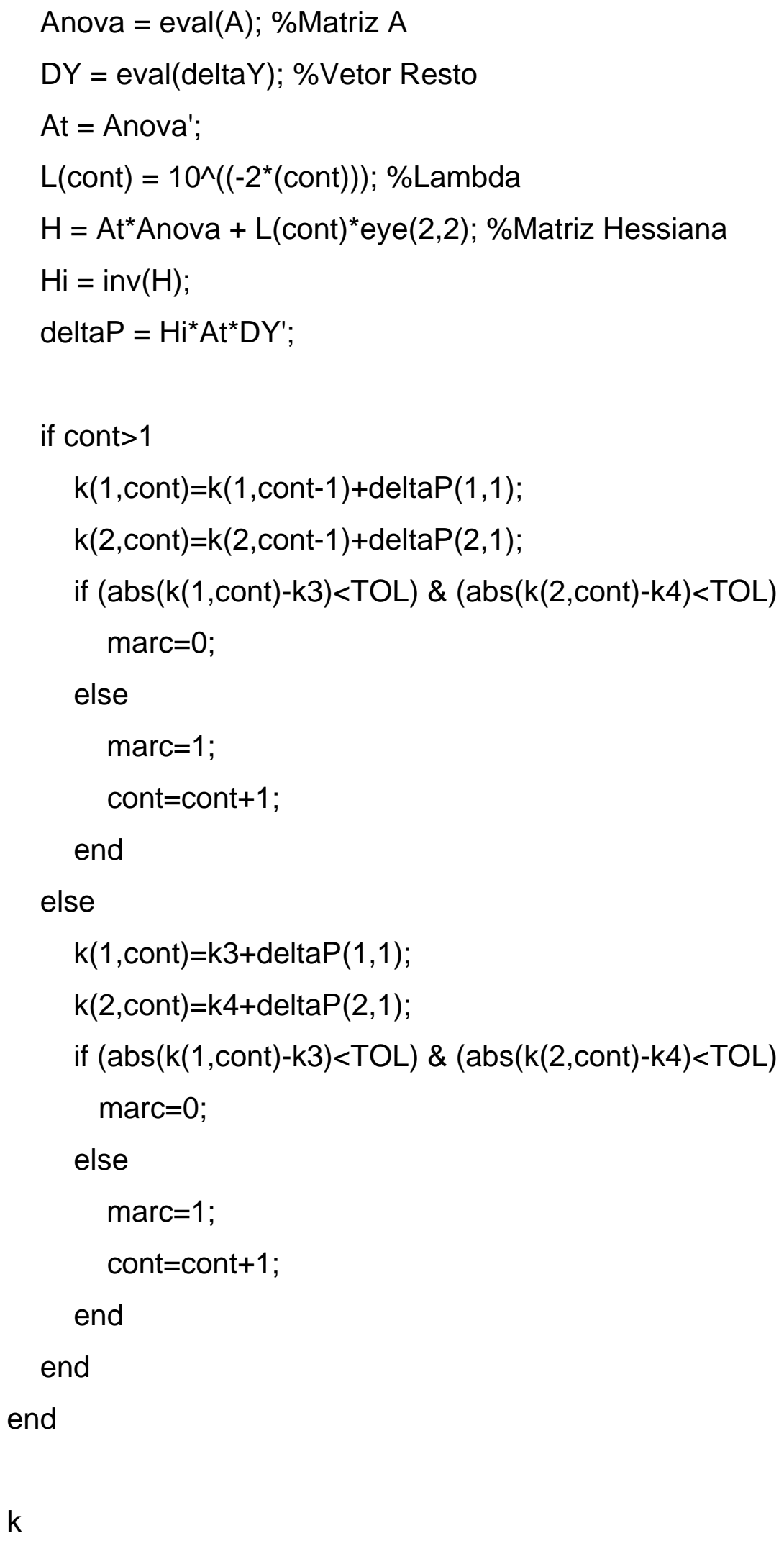

